\title{
A navegação de cabotagem no Brasil: uma análise geográfica da conjuntura do modal no início do século XXI
}

Rafael Oliveira Fonseca

Universidade Universitária de Campo Grande, Universidade Estadual de Mato Grosso do Sul, Brasil.

Recebido: 2 de abril de 2018. Aceptado: 11 de mayo de 2018.

\begin{abstract}
Resumo
A circulação é um dos elementos intrínseco aos processos produtivos e se estabelece como uma das premissas do período atual orientado pela racionalidade capitalista mundializada. Nesse sentido, toda modalidade de transporte se torna um componente imperativo da contemporaneidade. Este artigo visa analisar alguns pontos da atual situação da navegação de cabotagem de carga no Brasil, uma modalidade aquaviária de transporte, que pode ser entendida como um objeto constitutivo das dinâmicas de circulação dos fluxos materiais no país. Essa análise visa aprofundar o entendimento sobre as relações entre uso, regulação e organização do território contemplando: o papel da circulação e sua importância na estruturação do território, as recentes ações estatais para essa modalidade de transporte, as estatísticas contemporâneas de circulação de mercadorias por meio da cabotagem, os principais fixos, fluxos e circuitos espaciais da produção que se utiliza do modal, bem como, a principal companhia brasileira que atua na cabotagem na atualidade. Por fim, aponta-se algumas considerações finais reforçando que a cabotagem poderia ser ampliada de maneira a se favorecer das características físicas do território nacional, sobretudo pelo fato do país possuir uma imensa costa atrelada a uma concentração populacional predominantemente litorânea.
\end{abstract}

\section{The Cabotage in Brazil: a geographical analysis of modal conjuncture at the beginning of the 21st century.}

\footnotetext{
Abstract

Circulation is one of the elements intrinsic to productive processes and is established as one of the premises of the current period oriented by the globalized capitalist rationality. In this sense, every modality of transportation becomes an imperative component of contemporaneity. This article aims at analyzing some points of the current situation of cabotage in Brazil, a maritime modal of transportation, which can be understood
}

\section{Palavras-chaves}

Circulação

Fixos

Fluxos

Transporte aquaviário

Cabotagem
Keywords

Circulation

Fixed

Flows

Maritime transportation

Cabotage

Palabras claves

Circulación

Fijos

Flujos

Transporte marítimo

Cabotaje 
as an object that constitutes the dynamics of circulation of the material flows in the country. This analysis aims to expand the understanding of the relations between use, regulation and organization of the territory contemplating: the role of circulation and its importance in structuring the territory, the recent state actions for this modality of transport, the contemporary statistics on the circulation of goods by cabotage, the main fixed, flows and space circuits of the production that uses the modal, as well as the main Brazilian company that operates in cabotage today. Finally, some final considerations suggest that cabotage could be expanded to benefit from the physical characteristics of the national territory, especially by the fact that Brazil has an immense coastline that is linked to a predominantly coastal population.

\section{Introdução}

O Brasil possui uma dimensão territorial continental. Afirmação cotidianamente utilizada ao se referir ao quinto país do mundo em extensão territorial, sendo o maior da América Latina e do Hemisfério Sul. Mais extenso inclusive que todo o território da Oceania, que é classificada como um continente. Talvez por isso a afirmação inicial pareça fazer sentido a despeito do debate conceitual do que seria um continente.

Dessa forma, o Brasil, caracterizado por possuir um imenso território (Figura 1), possui uma considerável extensão longitudinal e latitudinal que supera os quatro mil quilômetros cada, uma fronteira terrestre que ultrapassa os 15 mil quilômetros, além de um longo litoral que apresenta mais de sete mil quilômetros de costa (Ibge, 2015).

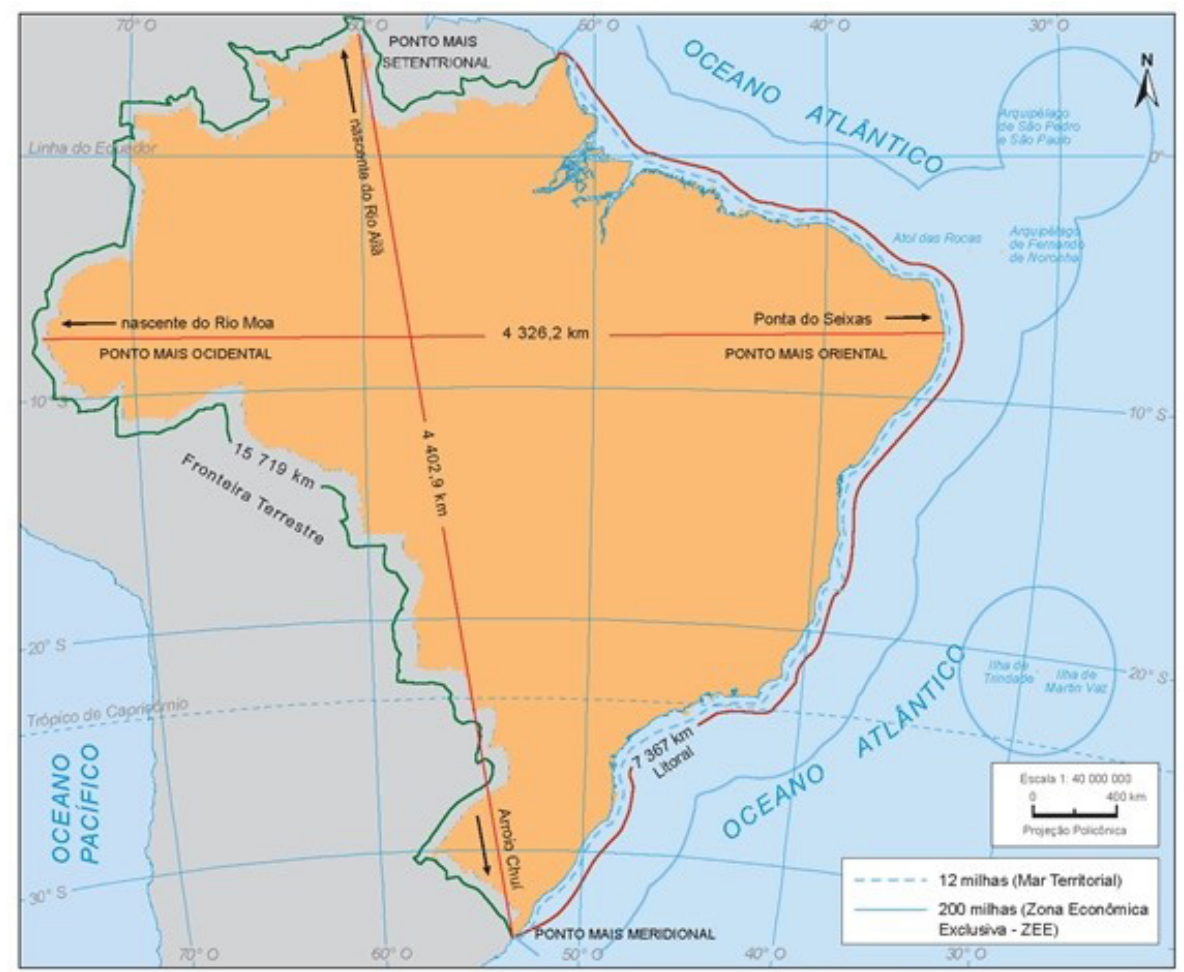

Figura 1. Fronteiras e pontos extremos. Fonte: IBGE (2015) 
No entanto, apesar da grande extensão territorial, a ocupação demográfica do país não é uniforme. Há uma concentração populacional predominantemente litorânea com amplas extensões costeiras continuamente ocupadas (Figura 2), onde se localizam aglomerações de considerável densidade populacional (Moraes, 2007), a maioria das principais cidades e centros consumidores do país. Segundo IBGE (2015), aproximadamente 58\% dos habitantes do Brasil habitam uma faixa litorânea de até duzentos quilômetros da costa.

Essa ocupação litorânea é uma herança do processo de colonização do atual território brasileiro realizado por Portugal a partir do século XVI, que concebeu uma estrutura de ocupação e povoamento no sentido do litoral para o interior, priorizando, dessa forma, os espaços costeiros e de modo consequente as áreas naturalmente favoráveis e/ou propícias às atividades portuárias.

Segundo Moraes (2000), a oportuna qualidade marítima do colonizador contribuiu para difusão dessa lógica ocupacional sobre o território brasileiro, promovendo uma unidade territorial via oceano. Elemento que minimizou, no princípio, a necessidade do emprego de modais terrestres em larga escala, apesar das inúmeras dificuldades posteriores encontradas para a integração econômica das áreas interioranas do território (Silva, 1941) com o avanço do processo colonizador.

É relevante destacar que uma dinâmica territorial intrinsecamente vinculada a região costeira não ocorreu exclusivamente no Brasil, pelo contrário, a circulação através do modal aquaviário, seja de mercadorias ou de informações, faz parte da história da humanidade e reflete a ocupação humana, do passado e do presente, em todos continentes.

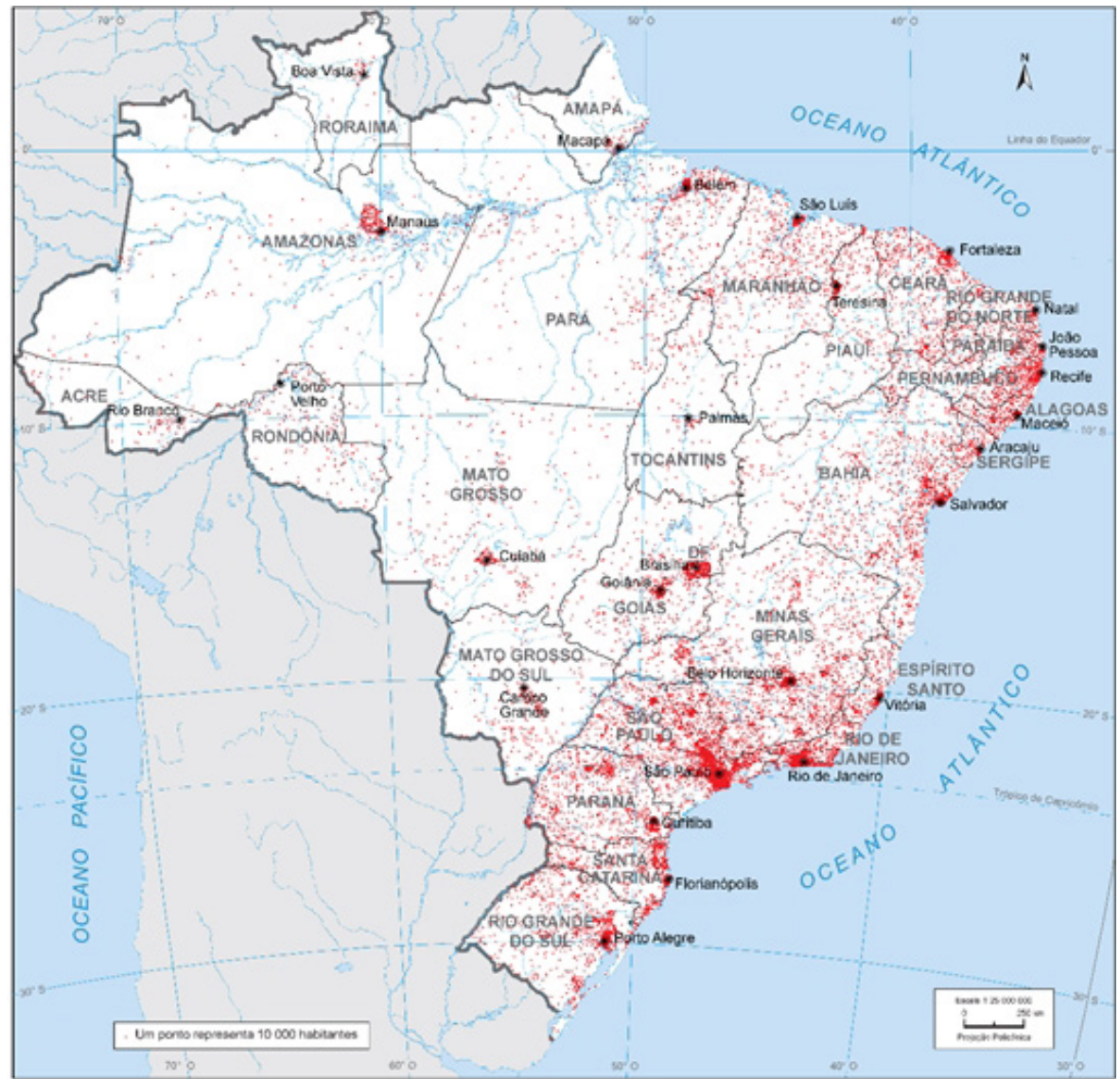

Figura 2. Distribuição da população brasileira (2014). Fonte: IBGE (2015) 
O mar foi o caminho natural para que o Homem atingisse todas as terras emersas do planeta que não são plenamente conectadas. Em vista disso, a integração social da humanidade em escala global ocorreu pela via marítima [e também fluvial], assim, o transporte aquaviário foi um dos primeiros modais a serem utilizados comercialmente em larga escala pela raça humana (Neto, 2010).

Esse histórico reforça o papel secular das regiões portuárias, sejam marítimas ou fluviais, como nós vitais das redes comerciais multiescalares, interligando economias locais, regionais, nacionais e internacionais muitas vezes a partir de um mesmo ponto do território, tanto no passado como no presente.

Sendo assim, o Atlântico e os principais rios foram, tanto no período colonial como após a independência, os caminhos naturais e acessíveis para a promoção da fluidez de grande parte das mercadorias, dos fluxos migratórios diversos e também de inúmeras correntes do pensamento, ou seja, foram vias fundamentais de circulação material e imaterial.

Por isso, compreende-se que a rede urbana brasileira, em seu princípio, era uma sucessão de núcleos litorâneos, cada um estruturando eixos de penetração na hinterlândia ${ }^{1}$ (Cruz, 2006b). É nesse cenário que emerge a importância das navegações por cabotagem para o território brasileiro, que formavam no passado a verdadeira espinha dorsal do sistema de viação do Brasil (Prado Jr., 1977 [1942]).

Essa modalidade de transporte aquaviário é utilizada há séculos em todo o mundo, até por isso a adoção desse vocábulo é encontrada em diversos idiomas. Com base na etimologia, há inúmeras explicações para o termo, mas regularmente sucedem-se sobretudo duas: a primeira diz respeito à ideia da navegação e do transporte marítimo costeiro de cabo-a-cabo (penínsulas), por isso expressão cabotagem; enquanto que a segunda, refere-se a Sebastião Caboto, italiano, navegador do século XVI, que explorava terras pelas "margens", prática que por isso teria ficado conhecida como cabotagem.

A despeito da origem da palavra, no Brasil o termo cabotagem se refere exclusivamente a uma modalidade de transporte aquaviário. Mas há algumas diferenças em relação à definição desse modal ser nacional ou internacional, sobretudo em relação ao período histórico no qual o mesmo é citado.

Por isso, para desenvolver a análise proposta por este trabalho, considera-se a definição considerada pela Agência Nacional de Transportes Aquaviários do Brasil (Antaq), que se tem como base a Lei Federal no 10.893/04 (Brasil, 2004) e que define a navegação de cabotagem como: toda navegação realizada entre portos brasileiros, utilizando exclusivamente a via marítima ou a via marítima e as interiores (fluviais).

Assim, neste trabalho concebe-se cabotagem como todo transporte aquaviário exclusivamente "nacional" que se realiza "totalmente ou parcialmente pela via marítima" costeira, podendo, dessa forma, percorrer também trechos de vias fluviais.

Essa mesma Lei Federal (Brasil, 2004) também define as outras duas modalidades aquaviárias sob a esfera de atuação da Antaq: 1) a navegação de longo curso, que se realiza entre portos brasileiros e portos estrangeiros, sejam marítimos, fluviais ou lacustres, ou seja, é todo transporte aquaviário internacional não importando qual via aquaviária utilizada; e, 2) a navegação interior, que se realiza exclusivamente entre portos brasileiros usando somente as vias interiores, ou seja, é todo transporte aquaviário nacional que se realiza em lagos e rios sem pelo mar.

Isso posto, delineia-se que no Brasil a navegação de cabotagem foi um elemento fundamental da era pré-técnica do território colonial brasileiro e continua sendo parte do
1. Hinterlândia é definido como a área de influência de uma cidade portuária que, por concentrar significativa atividade econômica, pode engendrar uma rede urbana, constituída por centros urbanos menores, incluindo sua rede de transportes (Santos, 2008 [1981]). 
sistema de circulação aquaviário da marinha mercante ${ }^{2}$ nacional, tendo como características principais: 1) sob a perspectiva econômica, o baixo custo relativo devido sua alta capacidade de carga; 2) sob a perspectiva temporal, não priorizar a velocidade em seus deslocamentos (Contel, 2001); 3) sob a perspectiva técnica, demandar a existência de sistemas de engenharias fixos que possibilite as operações de transbordo nas embarcações no um contexto contemporâneo do transporte multimodal de cargas.

Assim, observa-se que historicamente o transporte de cabotagem foi um dos principais modais utilizado no Brasil até primeira metade do século XX, quando as malhas ferroviárias se voltavam predominantemente para a interiorização do território, e, sobretudo as malhas rodoviárias ainda se encontravam em formação.

No entanto, a matriz de transporte que se consolida no Brasil a partir da metade do século passado deixa os modais aquaviários até o presente em uma posição marginal em relação aos principais modais terrestres (Figura 3).

A cabotagem, ainda que em uma posição secundária, não fica estagnada se inserindo no contexto de um "novo" padrão de organização do território posto ao Brasil frente à dinâmica das mudanças econômicas, políticas e sociais ocorridas na maior parte do mundo nas últimas décadas.

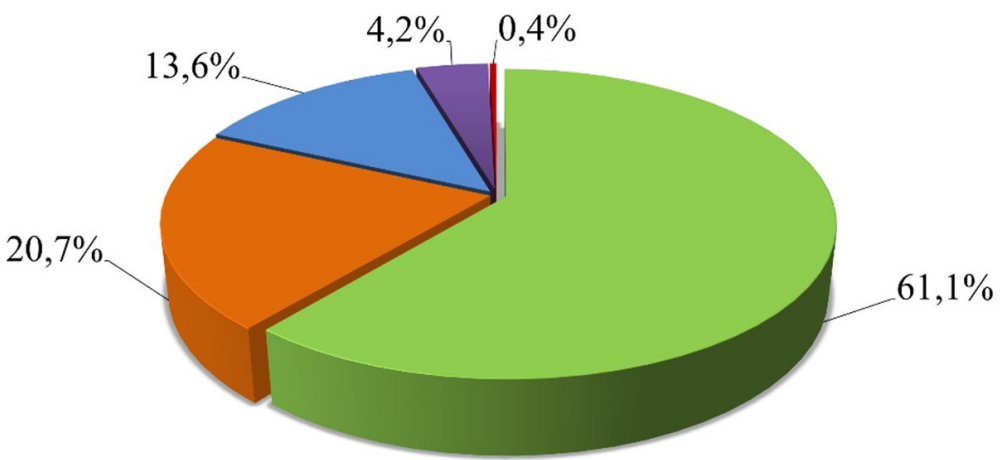

$\square$ Rodoviário $\square$ Ferroviário $\square$ Aquaviário $\square$ Dutoviário $\square$ Aéreo

Figura 3. Matriz de transportes de cargas do Brasil em 2013. Fonte: Elaboração própria (CNT, 2014).

Um padrão ordenado, dentre outros fatores, na busca por uma maior racionalidade e fluidez territorial em decorrência da intensificação dos fluxos materiais e imateriais oriundos de uma inserção cada vez mais pujante do país no mercado capitalista mundializado.

Nesse sentido, concebe-se que o território é reordenado constantemente devido, dentre outros fatores, às demandas econômicas de agentes hegemônicos corporativos inseridos nos diversos circuitos espaciais da produção, ${ }^{3}$ que exigem a realização de operações logísticas cada vez mais eficazes e lucrativas nas quais se insere logicamente todos modais de transportes, dentre os quais, a navegação de cabotagem.

Nesse contexto, o objetivo deste artigo é analisar alguns aspectos da dinâmica da circulação material que se realiza no Brasil através da navegação de cabotagem de carga, destacando: o papel da circulação e sua importância na estruturação do território, as recentes ações estatais para essa modalidade de transporte, as estatísticas contemporâneas de circulação de mercadorias por meio da cabotagem, os principais fixos, fluxos e circuitos espaciais da produção que se utiliza do modal, bem como, a principal companhia brasileira que atua na cabotagem na atualidade.
2. Marinha mercante pode ser definida como a frota de embarcações civis utilizadas para o transporte de mercadorias, ou seja, são as embarcações dedicadas essencialmente às atividades econômicas de circulação material, excluindo a frota dedicada às atividades: militares (Marinha de Guerra), pesqueiras (Marinha de Pesca), a frota de apoio marítimo (ex: rebocadores), plataformas de petróleo, e aquela dedicada às atividades de esportes náuticos e outras atividades recreativas (marinha de recreio).
3. Para Santos e Silveira (2001, p. 143) os circuitos espaciais da produção “[...] são definidos pela circulação de bens e produtos e, por isso, oferecem uma visão dinâmica, apontando a maneira como os fluxos perpassam o território". 


\section{Circulação, fluidez territorial e operações logísticas}

O meio geográfico nas primeiras décadas do século XXI se caracteriza, em grande medida, pelo que Santos (1996) destaca como a convergência da técnica, da ciência e da informação. Em um contexto no qual os sistemas de objetos técnicos são concebidos com base na ciência e possuem uma técnica informacional que servem às diversas modalidades e às variadas etapas da produção, amoldando-se, dessa forma, como alicerce à aceleração dos fluxos capitais, mercadorias, informações, pessoas etc.

Nesse cenário, a circulação se destaca como elemento intrínseco e indissociável dos processos produtivos, haja vista que progressivamente se estabelecem as possibilidades para especialização dos lugares não havendo mais, dessa maneira, a necessidade de se produzir localmente todo o tipo de necessidades e demandas, estabelecendo uma intensa divisão territorial do trabalho (Santos, 1996). Por isso, segundo Castillo e Frederico (2010), a forma histórica da atual divisão territorial do trabalho corresponde a uma configuração, também historicamente determinada, de circulação.

Portanto, a atual divisão territorial do trabalho contribui para o aumento dos fluxos materiais e imateriais que ocorrem em espaços cada vez mais amplos do mercado mundializado, maximizando as possibilidades de espraiamento geográfico das atividades econômico-produtivas.

Uma conjuntura na qual as redes de circulação e comunicação contribuem cada vez mais para modelar o cenário espaço-temporal que é todo o território (Raffestin, 1993 [1980]).

Todavia, isso não ocorre, de forma equivalente em todos os lugares, portanto se faz necessário compreender que a circulação atua como uma das bases da diferenciação geográfica (Arroyo, 2006), de uma forma substancialmente acentuada na atualidade.

Não é apenas no período atual que a circulação possui relevância. Fernand Braudel (1996 [1979]), ao analisar aspectos dos instrumentos da troca dentre os séculos XV e XVIII, demonstrou a influência da circulação nas atividades econômico-produtivas daquele momento histórico. Segundo o autor, somente através da circulação é possível ocorrer a ligação entre o universo da produção e do consumo, ou seja, a circulação já era no passado o elo fundamental entre o local de produção e o consumo dos produtos.

Da mesma forma, Camille Vallaux (1914) destaca o mérito da circulação através de outra perspectiva, destacando seu caráter político e o papel do Estado, pois este cria, altera, elimina, e regula os caminhos de acordo com seus interesses e daqueles que este representa.

Enquanto que Harvey (2005), guiado pelas obras de Marx, evidencia que o transporte, por também produzir valor, faz parte diretamente do processo produtivo e contribui para as transformações das relações espaciais e, consequente hierarquização dos lugares. De acordo com Santos (2003 [1979]), o transporte não é uma mercadoria passível de armazenamento, portanto se realiza exatamente no fenômeno da circulação.

Assim, os fluxos de bens, pessoas e informações cada vez mais intensos, requerem um suporte material e técnico visando trafegar pelo território com a máxima fluidez possível, pois cada atividade produtiva exerce uma forma de interferência incorporando as influências dos territórios (Lamoso, 2009). Pode-se dizer que há uma demanda cada vez maior por sistemas de movimento no território, sobretudo daqueles que promovam a circulação material, ocasionando por conseguinte, na expansão ou na complexidade das interações espaciais. ${ }^{4}$ 
Desse modo, no período atual a circulação emerge como um elemento imperativo cercado pela racionalidade econômica capitalista, na busca permanente por uma maior fluidez e porosidade territorial, com o objetivo de conceber espaços quase ideais, com a finalidade de abolição total dos obstáculos, promovendo uma livre circulação das mercadorias. Aspiração do mercado mundializado em decorrência de sua vultuosa demanda por fluxos internacionais em sua busca incessante e perene por crescimento econômico e maximização dos lucros.

Nessa conjuntura, os lugares buscam de numerosas maneiras se inserirem nesse mercado, quase sempre permitindo intervenções estrangeiras ao nível local, interferindo na fluidez e porosidade territorial dos lugares.

Segundo Arroyo (2001), a fluidez territorial exprime a qualidade daqueles territórios que possuem a capacidade de propiciarem uma aceleração cada vez maior dos fluxos a partir de uma base material estruturada por um conjunto de objetos concebidos especialmente para promoverem a circulação.

Por sua vez, a porosidade territorial contribui para definir as qualidades dos territórios em suas relações com o exterior, ou seja, também permitem uma aceleração crescente dos fluxos, mas "[...] a partir de uma base institucional incumbida da regulação do movimento" (Arroyo, 2001:143), com o objetivo de aprofundar a inserção estrangeira nos territórios.

Grande parte dos circuitos espaciais da produção demandam infraestruturas que são concebidas para servirem de suporte à produção, à circulação e ao consumo das mercadorias comandadas pelas atividades produtivas.

Por consequência, são objetos técnicos que atuam como um dos elementos organizadores e produtores do espaço, definindo características e influenciando no desenvolvimento econômico do processo de acumulação (Lamoso, 2009), que não ocorre de forma homogênea pelo espaço geográfico através dos sistemas de movimento do território.

Nesses sistemas, as operações logísticas são elementos dos circuitos espaciais da produção como planejamento e gestão, ou seja, como uma estratégia corporativa, e não simplesmente como um fixo ou um fluxo (Silveira, 2009).

Do ponto de vista territorial, essas operações operam como um conjunto de competências infraestruturais, institucionais e organizacionais que possibilitam competitividade a um espaço geográfico, aos agentes econômicos atuantes e aos circuitos produtivos que dele fazem uso (Castillo, 2011). Nesse sentido, a logística deveria ser assimilada como um conjunto de atividades corporativas que orientam a movimentação de uma rede produtiva complexa (Sposito, 1999), inseridas consequentemente em circuitos espaciais da produção que demandam uma circulação cada vez mais eficaz e lucrativa.

Nesse contexto, destaca-se que qualquer operação logística atua como um vetor de ordem e desordem (Trevisan, 2007), pois contribui para a fragmentação do território, para a hierarquização dos lugares e, de modo consequente para a competitividade territorial em decorrência da especialização de, por exemplo, locais portuários.

Os portos, os Terminais de Uso Privativos (TUPs) e a navegação de cabotagem não podem ser analisados somente como sistemas de engenharia que possuam como objetivo servirem apenas os locais onde se realizam a movimentação, o armazenamento e 
o transbordo de cargas, ou seja, apenas como elementos integrantes das operações logísticas. Conjuntamente representam um elo na (re)estruturação da matriz de transporte brasileira no contexto da intermodalidade $e^{5}$ e da multimodalidade ${ }^{6}$ característico do atual período, contribuindo consideravelmente para a elevação da fluidez territorial no Brasil.

Apesar da cabotagem não estar dentre os principais modais do transporte nacional no período atual, ainda assim é utilizada em larga escala por alguns setores produtivos em específico, conforme será abordado adiante, tendo, dessa forma, influência significativa em pontos específicos do território, contribuindo para a diferenciação geográfica e a consequente hierarquia dos lugares.

Cruz (2006a) ressalta que os portos com o suceder dos séculos adquiriram novas funções e com isso estabeleceram novas relações com seu entorno, bem como com lugares, mesmo que muito distantes, desempenhando assim um papel cada vez mais amplo.

Por isso, um porto marítimo não pode ser compreendido apenas como um lugar de trânsito, uma etapa do transporte de mercadorias ou mesmo como um ponto de contato entre dois modos de transporte, pois suas atividades, estruturas, e seus usuários, refletem a grande diversidade de produtos que o mesmo recebe, a multiplicidade de navios que perpassam, e a complexidade de suas ligações marítimas e terrestres (Fischer, 2008 [1963]), portanto o dinamismo, as interações espaciais e suas áreas de influências são intensas.

Em suma, pode-se concluir que a navegação de cabotagem, como um sistema de movimento, está inserida na complexa dinâmica da circulação e das cidades, junto a sua hinterlândia, possuindo papel preeminente como elemento da produção de alguns circuitos produtivos. Trata-se, portanto, de um campo de ações que articula as demandas da competitividade territorial dos grandes agentes corporativos, sob o consentimento dos Estados, com as possibilidades oferecidas pelos modernos sistemas de objetos e técnicas quase sempre oriundos de vultuosos investimentos públicos.

\section{Ações públicas na cabotagem brasileira no início do século XXI}

No início do século XXI, logo na primeira década, iniciou-se um novo ciclo governamental no Brasil aliada a uma conjuntura macroeconômica internacional que colocou o Brasil em um momento ímpar de sua história, que resultou no alargamento de importância política e econômica no cenário internacional.

Em relação ao transporte aquaviário nacional, em 2001, ocorre um importante ato público com a criação Antaq, ${ }^{7}$ como uma autarquia constituinte da Administração Federal indireta vinculada na atualidade ao Ministério dos Transportes, Portos e Aviação Civil. Na esfera de atuação da Antaq está o modal aquaviário como um todo, seja ele: fluvial, lacustre, de travessia, de apoio marítimo, longo curso, e cabotagem; bem como atuar sobre os sistemas de engenharias vinculados a essa modalidade de transporte, como os portos e os terminais portuários de uso privativos.

A autarquia detém uma função, sobretudo técnica e regulatória baseada em uma dezena de atribuições, sendo o representante do poder público na regulação, supervisão e fiscalização da navegação de cabotagem brasileira, atuando também no incentivo ao setor, promovendo parte da política setorial do modal determinada pelo Poder Executivo (Brasil, 2001; 2013).
5. A intermodalidade é o transporte que se realiza a partir da utilização conjunta de mais de um modal, mas que utiliza documentos fiscais individuais para cada tipo de modal.

6. A multimodalidade ou o transporte multimodal de cargas é definido pela Lei Federal nº 9.611 de 19 de fevereiro de 1998 que: “Dispõe sobre o Transporte Multimodal de Cargas e dá outras providências". Artigo $2^{\circ} \mathrm{O}$ Transporte Multimodal de Cargas é aquele que, regido po um único contrato, utiliza duas ou mais modalidades de transporte, desde a origem até o destino, e é executado sob a responsabilidade única de um Operador de Transporte Multimodal (Brasil, 1998). Felipe Jr e Silveira (2009) ressaltam que a multimodalidade é importante no contexto da nova lógica da dinâmica territorial, pois permite a articulação entre o local e o global, os fluxos materiais mediante a formação de redes, a intermediação entre produtor e mercado, além da reprodução do capital.

7. Lei Federal 10.233 de 2001: “Dispõe sobre a reestruturação dos transportes aquaviário e terrestre, cria o Conselho Nacional de Integração de Políticas de Transporte, a Agência Nacional de Transportes Terrestres, a Agência Nacional de Transportes Aquaviários e o Departamento Nacional de Infraestrutura de Transportes, e dá outras providências" (Brasil, 2001). 
Nesse contexto, com o apoio técnico das agências reguladoras e das entidades integrantes da Administração Federal Direta, o Estado indicou que retomaria seu papel em setores que, até certo ponto, foram rechaçados quase que exclusivamente as ações e decisões da iniciativa privada no decorrer da década de 1990.

A partir da década passada, no Brasil ocorreram consideráveis volumes de investimentos no setor de transportes por meio de significativa somas monetárias através de financiamento do BNDES (Banco Nacional de Desenvolvimento Econômico e Social) aplicados, por exemplo, na indústria naval e nos portos, visando a promoção concomitante do desenvolvimento da navegação mercante brasileira.

Um dos elementos marcantes nesse sentido foi o Programa de Aceleração do Crescimento (PAC), lançado em 2007 pelo Governo Federal. O PAC consistiu em um conjunto de medidas majoritariamente estatais que visavam, como um plano estratégico de governo, contribuir para o resgate de investimentos em setores estruturantes (Brasil, 2010) e consequentemente para retomada do papel do Estado como agente indutor do desenvolvimento socioeconômico do país.

Em vista disso, vultosos investimentos em infraestrutura de transporte foram uma das bases do Programa, sobretudo para setores identificados como "gargalos" do setor de transportes do país, em consonância com as estratégias previstas no Plano Nacional de Logística e Transportes (PNLT), elaborado pelos Ministérios dos Transportes e da Defesa em 2006 (Brasil, 2007; 2009).

O Balanço final da primeira fase do PAC que durou quatro anos (2007-2010) foi divulgado em novembro de seu último ano (Brasil, 2010). As ações foram divididas em três setores infraestruturais: 1) Logística, 2) Energética, e 3) Social e Urbana. No eixo Logística, que contemplou os principais modais de transporte do país, ocorreram investimentos de $\mathrm{R} \$ 65,4$ bilhões. ${ }^{8} \mathrm{O}$ volume financeiro destinado especificamente à marinha mercante foi de $\mathrm{R} \$ 17$ bilhões com o objetivo de promover, dentre outros fatores, a revitalização da indústria naval brasileira, através do financiamento de centenas de embarcações.

Em suma, detalhadamente, no período foram concluídas 107 embarcações, dentre projetos envolvendo o Programa de Modernização e Expansão da Frota (Promef) ${ }^{9}$ e o Fundo da Marinha Mercante (FMM), 93 estavam em construção e havia a assinatura de contratos de financiamentos de mais 101 unidades, totalizando 301 embarcações, além da construção e modernização de cinco estaleiros, conforme o Quadro 1 (Brasil, 2010).

8. Previsão em 31 de dezembro de 2010 (Brasil, 2010).

9. O principal programa do setor naval brasileira, o Promef, tem como base a construção de navios no Brasil com índice de nacionalização de no mínimo $65 \%$ almejando o aumento da competitividade e visa reimpulsionar a cadeia produtiva do setor no Brasil, além de atender as demandas da Petrobras na navegação de longo curso, fluvial e de cabotagem. 
Quadro 1. Evolução dos contratos do Programa de Financiamento da Marinha Mercante do PAC no período de 2007-2010 (dados da previsão para 31/12/2010). Fonte: organização própria com base no Balanço de 4 anos (2007-2010) do PAC (Brasil, 2010).

\begin{tabular}{|c|c|c|c|}
\hline \multicolumn{4}{|c|}{ PAC - Embarcações } \\
\hline Fase & Qtde & Tipo de Embarcação & UF (quantidade) \\
\hline \multirow{5}{*}{ Concluídos } & 35 & Carga & Pará (21), Rio de Janeiro (6), Amazonas (5) e Rio Grande do Sul (3) \\
\hline & 35 & Apoio à Navegação & Santa Catarina (21), São Paulo (13) e Rio de Janeiro (1) \\
\hline & 33 & Apoio a Plataforma & Santa Catarina (16), Rio de Janeiro (13) e São Paulo (4) \\
\hline & 3 & Pesca & Santa Catarina (3) \\
\hline & 1 & Passageiro & Santa Catarina (1) \\
\hline subtotal & 107 & & \\
\hline \multirow{4}{*}{ em construção } & 46 & Carga & \multirow{7}{*}{$\begin{array}{l}\text { Rio de Janeiro (47), Pará (43), São Paulo (29), Santa Catarina (24), Ceará } \\
\text { (17), Pernambuco (15), Amazonas (13), Sergipe (4) e Bahia (2) }\end{array}$} \\
\hline & 23 & Apoio à Navegação & \\
\hline & 23 & Apoio a Plataforma & \\
\hline & 1 & Passageiro & \\
\hline \multirow{3}{*}{ Contratados } & 27 & Carga & \\
\hline & 47 & Apoio à Navegação & \\
\hline & 27 & Apoio a Plataforma & \\
\hline subtotal & 194 & & \\
\hline TOTAL & 301 & & \\
\hline \multicolumn{4}{|l|}{ PAC - Estaleiros } \\
\hline Fase & Qtde & & Observação \\
\hline em construção & 3 & $\begin{array}{l}\text { Implantação/ } \\
\text { Modernização }\end{array}$ & $\begin{array}{c}\text { Atlântico Sul (Suape/CE), Navship (Navegantes/SC) e STX (Rio de } \\
\text { Janeiro/RJ) }\end{array}$ \\
\hline Contratados & 2 & Modernização & Ebin-Aliança (Rio de Janeiro/RJ) e Mauá (Rio de Janeiro/RJ) \\
\hline TOTAL & 5 & & \\
\hline
\end{tabular}

A primeira fase do PAC também resultou em investimentos de aproximadamente R \$ 790 milhões em portos, além de R \$ 1,09 bilhão nas hidrovias, destacando-se a construção das eclusas de Tucuruí/PA no Rio Tocantins que consumiram por volta de $95 \%$ do montante total, além da implantação de dez terminais hidroviários no Rio Amazonas (Brasil, 2010).

Relevante destacar que essas ações públicas sobre o setor naval ocorreram no contexto das descobertas de petróleo na camada Pré-sal do litoral brasileiro, dessa maneira, grande parte das iniciativas vinculadas à construção de navios no Brasil tem a Petrobras como elemento central, ressaltando o papel do Estado para o setor.

Apenas a Transpetro (Petrobras Transporte S.A.) encomendou, em 2006, 49 navios no Brasil dentro do Promef, dando sobrevida ao praticamente sucateado parque naval do estado do Rio de Janeiro após mais de 20 anos de recessão. No mesmo contexto, em 2008, a Petrobras realizou a contratação de mais 146 embarcações ao longo dos próximos 10 anos no contexto do Prorefam, Programa de Renovação da Frota de Apoio Marítimo (MEDINA et al., 2010).

Em 2011 o PAC ingressou em uma segunda fase (2011-2014), denominada PAC2 (Brasil, 2011; 2014). Estruturado desta vez em seis eixos, com um especifico e denominado Transportes, o PAC2 também contemplou um subeixo para a revitalização da indústria naval, mas que esteve inserido no eixo denominado Energia. 
Para o eixo Transportes foram aplicados R \$ 66,9 bilhões até $2014^{10}$ (Brasil, 2014), no entanto, não é possível identificar o montante exato investido em cada modal. As estimativas publicadas no Relatório de Lançamento PAC2 com a previsão preliminar dos investimentos prenunciavam que apenas $7,1 \%$ do total destinado para o eixo Transporte seria designado ao modal aquaviário (ao considerarmos a soma do que seria aplicado em portos e hidrovias), conforme sistematização do Quadro 2 (Brasil, 2011).

Quadro 2. Previsão preliminar dos investimentos do Eixo Transportes do PAC2. Fonte: Elaboração própria com base no Relatório de Lançamento PAC2 (Brasil, 2011)

\begin{tabular}{|l|c|c|}
\hline PAC2 - Eixo Transportes \\
\hline Modal & Rșbilhões & $\mathbf{( \% )}$ \\
\hline Rodovias & 48,4 & $46,3 \%$ \\
\hline Ferrovias & 43,9 & $42,0 \%$ \\
\hline Portos & 4,8 & $4,6 \%$ \\
\hline Aeroportos & 3,0 & $2,9 \%$ \\
\hline Hidrovias & 2,6 & $2,5 \%$ \\
\hline Equipamentos para Estradas Vicinais & 1,8 & $1,7 \%$ \\
\hline TOTAL & 104,5 & \\
\hline
\end{tabular}

Destarte, o montante investido no modal aquaviário foi aplicado em 49 empreendimentos com o objetivo de dar continuidade as ações de melhoria da eficiência portuária, a redução dos custos logísticos, incentivo aos investimentos privados, dentre outros. As principais execuções se referem a construção e ampliação de terminais marítimos, hidroviários e portos, bem como dragagens de aprofundamentos.

Da mesma forma, o eixo Energia previa no seu lançamento $\mathrm{R} \$ 36,7$ bilhões destinados ao subeixo da indústria naval, somando ações que abarcariam 544 embarcações e 29 estaleiros (Brasil, 2011), dando continuidade assim as ações do PAC 1 para o setor da indústria naval e ampliação da frota da marinha mercante nacional, sobretudo aquelas ligadas ao Promef, as demandas das operações da Petrobras e a exploração do Pré-sal, deixando os outros agentes da cabotagem em uma posição marginal.

No entanto, também não é possível identificar o valor investido de fato na Indústria Naval no período, contudo, o Balanço final da segunda fase do PAC (Brasil, 2014), aponta estatísticas relevantes com o financiamento: de 141 embarcações entregues, sendo oito petroleiros; 125 embarcações em construção; 234 contratadas com financiamento aprovado; e, faz menção ainda a possibilidade de contratação de outras 256 embarcações. Além disso, houve o financiamento de ações envolvendo 13 estaleiros.

Por fim, após 2015 o PAC ingressa em sua terceira fase, prevista para ocorrer até 2018, divididos nessa etapa novamente em três eixos denominados: infraestrutura Logística, infraestrutura Energética e eixo Social e Urbano (Brasil, 2018), já sob a gestão de um novo ciclo governamental após o afastamento da presidenta Dilma Rousseff em decorrência de um impedimento intricado de seu mandado.

O sexto balanço da terceira fase do PAC, divulgado em fevereiro de 2018 e pouco detalhado em comparação ao material elaborado nas duas primeiras fases do Programa, destaca que até o final de 2017 mais de R \$ 547,5 bilhões haviam sido investidos, sendo que R \$225,8 bilhões representam ações concluídas. Do total concluído, R \$ 16,2 bilhões são do eixo de infraestrutura Logística e R \$ 98,7 bilhões do eixo infraestrutura Energética, que contempla elementos da Marinha Mercante nacional vinculado ao setor de Petróleo e Gás (Brasil, 2018).
10. Previsão em 31 de dezembro de 2014 (Brasil, 2014). 
Em suma, o referido balanço destaca até o momento os investimentos realizados nos portos em obras concluídas, em andamento e/ou contratadas de: dragagem (11 obras e 5 projetos), construção, ampliação e modernização ( 25 obras e 9 projetos), além de algumas ações consideradas de inteligência logística (8 concluídas e 6 em andamento). Também são mencionadas 36 intervenções em corredores hidroviários e em 31 terminais fluviais (Brasil, 2018).

Por fim, destacam-se algumas ações atreladas a indústria naval, com ênfase para a conclusão de 276 embarcações, em geral, já contratadas na segunda fase do programa (Brasil, 2018). De forma geral, percebemos uma redução no ritmo de investimentos e também a produção de materiais públicos menos detalhados que sem dúvida são reflexos do atual momento político e econômico do país.

Assim, retomando o foco deste trabalho, verificamos que mesmo em uma posição marginal em relação aos modais terrestres, as modalidades de transportes aquaviárias, incluindo logicamente a cabotagem, foram objetos de vários planos estatais recentes no planejamento e expansão das infraestruturas no Brasil, inserindo-se desse modo na expansão da intermodalidade pelo país.

Nesse contexto intermodal, Felipe Jr. (2012) destaca que aos principais fatores que dificultam o avanço da cabotagem estão atrelados a sua dificuldade em concorrer com o modal rodoviário, que além da questão cultural (com modal rodoviário predominante no país), resistências frente as possibilidades de entregas no sistema "porta-a-porta", dentre outros fatores. Além do mais, as empresas de navegação preferencialmente investem na navegação de longo curso internacional por ser mais lucrativa e ser o foco do mercado mundializado.

No entanto, apesar das dificuldades, a recente retomada que ocorreu na indústria naval pode contribuir para expansão do modal aquaviário no Brasil, apesar desse setor ser fortemente atrelado as demandas da exploração petrolífera no Brasil conforme abordaremos adiante.

Apesar do cenário conturbado há alguns anos estimativas do setor naval previam atender uma demanda de 730 novas embarcações até 2020, com uma carteira predominante de encomendas para a exploração e produção de petróleo off-shore (navios petroleiros, navios sondas, plataformas petrolíferas, embarcações de apoio marítimo, dentre outros), fortalecendo os estaleiros em operação no país e subsidiando a construção de outros (Raspanti, 2012).

Assim, uma apreciação dos recentes investimentos em infraestruturas de transportes não depende exclusivamente da análise do tipo e volume da produção, mas também da sua origem e seu destino, tornando relevante levar em conta os processos de circulação e no caso da navegação de cabotagem, uma análise das suas operações na atualidade e dos fixos portuários vinculados as suas operações.

\section{Fixos e fluxos: uma rede técnica voltada para a circulação}

Segundo Santos (1996), no espaço geográfico há uma relação entre o que é fixo e o que é fluxo. Nesse sentido, os fixos seriam os instrumentos de trabalho das forças produtivas em geral, incluindo a mão de obra, isto é, os fixos nos oferecem bases relevantes para a análise do processo imediato do trabalho. Enquanto que os fluxos são os movimentos, a circulação, e desse modo, também nos oferecem informações que nos auxiliam na compreensão dos fenômenos da distribuição e do consumo. Por essa razão, a partir dos fixos e dos fluxos, pode-se abordar a produção, a circulação, a distribuição e consumo através da análise desses dois elementos (Santos, 1997 [1988]). 
Destarte, as circulações materiais e imateriais contemporâneas demandam bases técnicas que gradativamente se incorporam ao território capacitando cada região de novas qualidades e possibilidades organizacionais (Contel, 2001).

Isso não ocorre de forma aleatória, pelo contrário, realiza-se de forma seletiva e hierárquica com base nos interesses dos agentes hegemônicos, considerando-se que a propagação das inovações nunca se generaliza pelo espaço, contribuindo inevitavelmente para a especialização dos lugares.

Essa especialização é reflexo, em grande medida, das condições técnicas e sociais do espaço. Tendo os fluxos de informações papel primordial, os lugares se diferenciam e se hierarquizam porque são todos mundiais, e essa mundialidade decorre das relações tecidas entre esses lugares, que nunca são escolhidos por acaso. $\mathrm{O}$ mundo oferece as possibilidades, e o lugar oferece as ocasiões (Santos, 1994).

Nesse cenário, os portos e os Terminais de Uso Privativos são os principais fixos vinculados a navegação de cabotagem, e os fluxos resultantes são as movimentações das cargas que seguem pelas rotas decorrentes dessa modalidade de transporte, atualmente cooptada por atores coorporativos, que são aqueles que mais ativamente participam do processo.

\section{Fixos portuários no Brasil: alguns aportes}

Os pontos do território onde se verifica a convergência entre dois domínios de circulação, a terra e a água, são os portos (Rodrigue, Comtois e Slack, 2009), que por seu lado refletem as atividades realizadas nos continentes enquanto lugares de conexão entre os transportes terrestres e aquaviários, constituindo a diversidade e complexidade de ligações que por ele se realiza (Fischer, 2009 [1963]).

Nesse contexto, os portos a princípio parecem ser iguais ou ao menos similares, no entanto Bichou e Gray (2005) afirmam que suas funções podem ser bem diferentes, pois mesmo em um "simples" porto pode haver uma conjunto de serviços com propósitos e categorias diferenciadas.

No Brasil, segundo artigo $2^{\circ}$ da Lei Federal 12.815/2013 (Brasil, 2013), um Porto Organizado é um bem público construído e aparelhado para atender as necessidades de navegação, de movimentação de passageiros ou de movimentação e armazenagem de mercadorias, e cujo tráfego e operações portuárias estejam sob jurisdição de autoridade portuária. Atualmente o sistema portuário brasileiro é composto por 35 portos públicos marítimos ou fluviais (Antaq, 2017).

Em resumo, um Porto Organizado pode ser operado pelo Estado ou sob um regime de concessão pública ou arrendamento. No entanto, em todos os casos sua operação está sujeita a uma autoridade portuária, e o administrador do porto, seja quem for, se relaciona com os usuários por meio da prestação de serviço público mediante pagamento de tarifas.

Ressalta-se que os serviços prestados no Porto Organizado, apesar de tarifado, têm a natureza de serviço público e não podem ser excepcionados a qualquer usuário independentemente de sua natureza legal.

A Lei Federal 12.815/2013 (Brasil, 2013) também define que os Terminais de Uso Privativo são instalações portuárias exploradas mediante autorização e localizada fora da área do porto organizado. Em resumo, os TUPs são instalações construídas, em geral, pelo setor privado para a movimentação e armazenagem de mercadorias destinadas ao transporte aquaviário ou provenientes dele não sendo integrante do patrimônio de um Porto Organizado. 
Segundo a Antaq até 2016 haviam 180 TUPs autorizados a operarem no Brasil. Observa-se que há uma concentração maior de terminais nos Estados litorâneos da Região Sul e Sudeste, bem como nos dos rios da Bacia Amazônica (Figura 4).

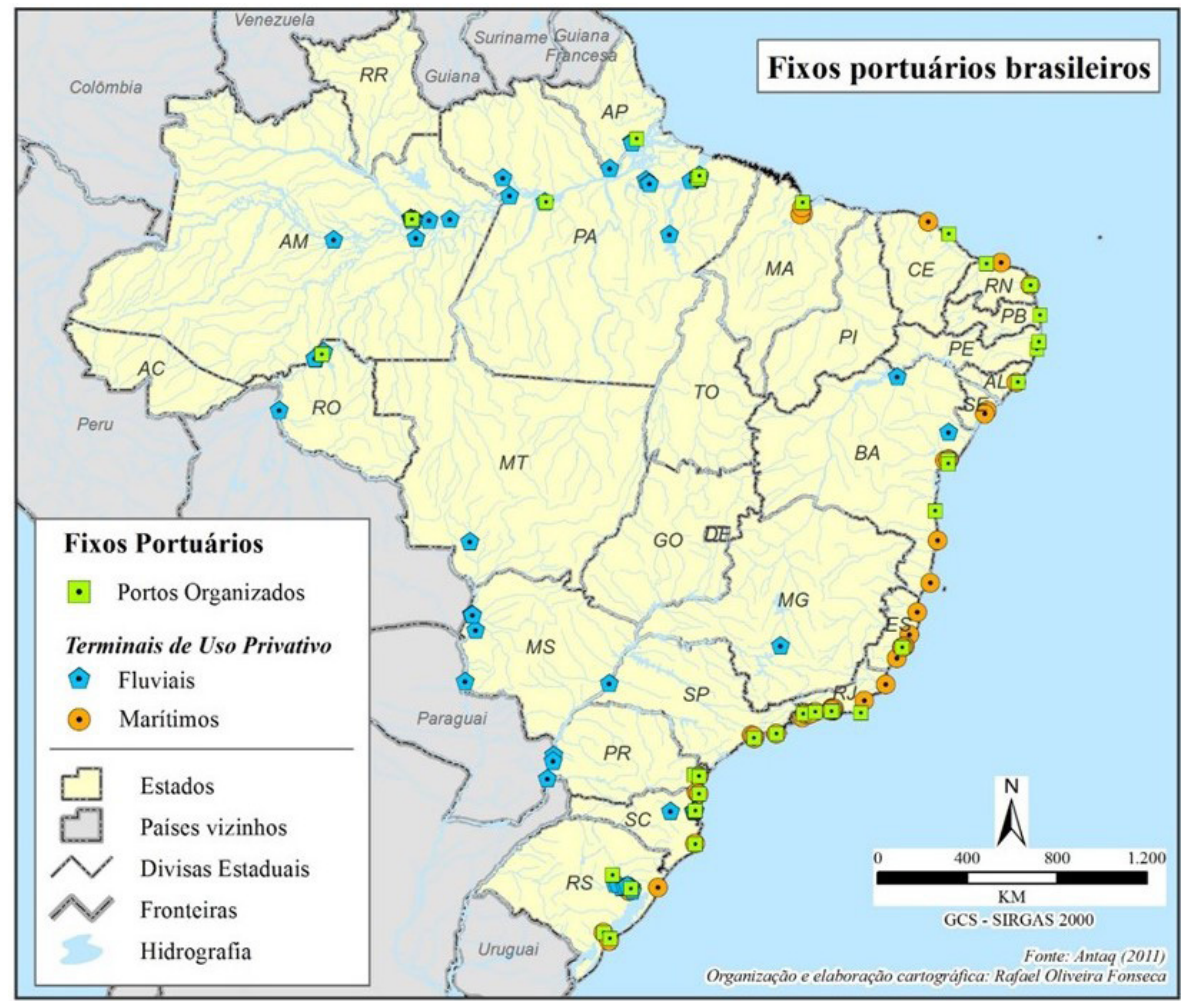

Figura 4. Principais Portos Organizados e Terminais de Uso Privativo do Brasil. Fonte: elaboração própria (Antaq, 2011).

\section{Fluxos e a circulação atual na cabotagem brasileira}

A figura 5 evidencia que há uma tendência de crescimento geral na movimentação de carga através da cabotagem no Brasil com base na tonelagem transportada. Observa-se que o volume de carga movimentada nos últimos vinte anos ultrapassou a marca dos 200 milhões de toneladas/ano em 2013 (Antaq, 2017)

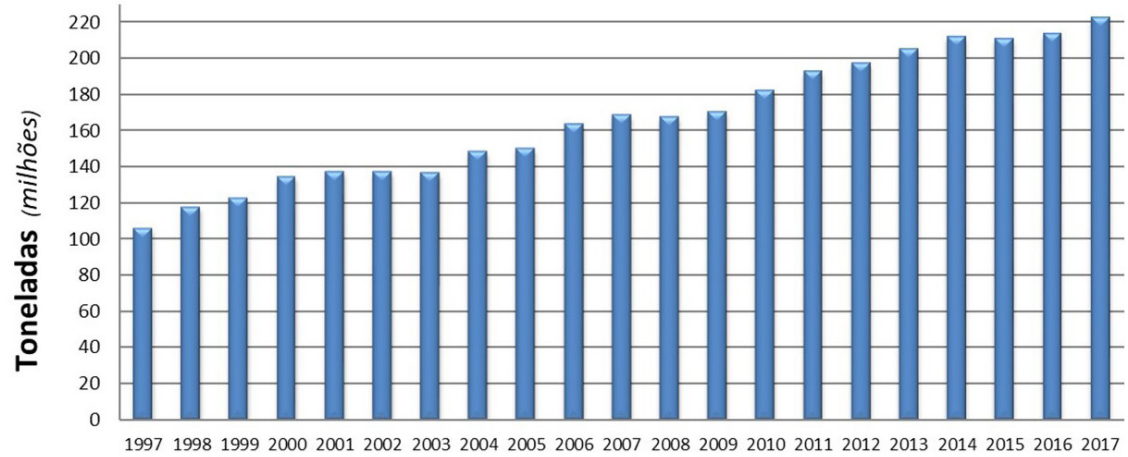

Figura 5. Movimentação de carga por navegação de cabotagem no Brasil de 1997 a 2017 em toneladas/ ano. Fonte: Elaboração própria com base nos Anuários Estatísticos Portuários da Antaq (Antaq, 2017). 
Da mesma forma, a evolução da frota brasileira de cabotagem apresenta-se em crescimento constante, ultrapassando a marca de 200 embarcações em 2016 (Antaq, 2017) (Figura 6).

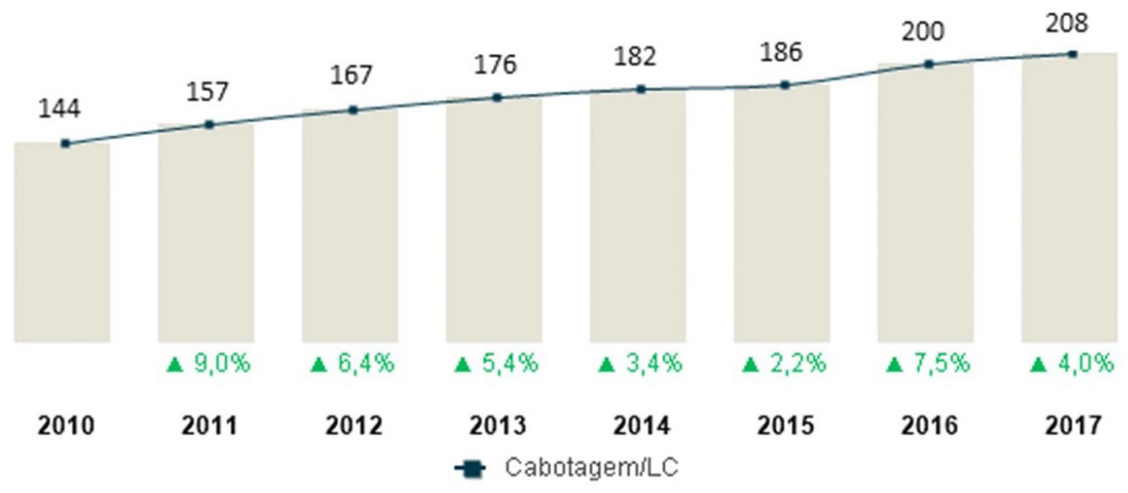

Figura 6. Evolução da frota de bandeira brasileira de cabotagem dentre 2010 e 2017. Fonte: Adaptação própria com base nos Anuários Estatísticos Portuários da Antaq (Antaq, 2017).

Em relação a frota, metade aproximadamente são de navios petroleiros, rebocadores/ empurradores ou barcaças. Outros $20 \%$ são de navios de carga geral e porta contêiner e o restante do percentual se divide dentre vários outros tipos de embarcações (Figura 7).

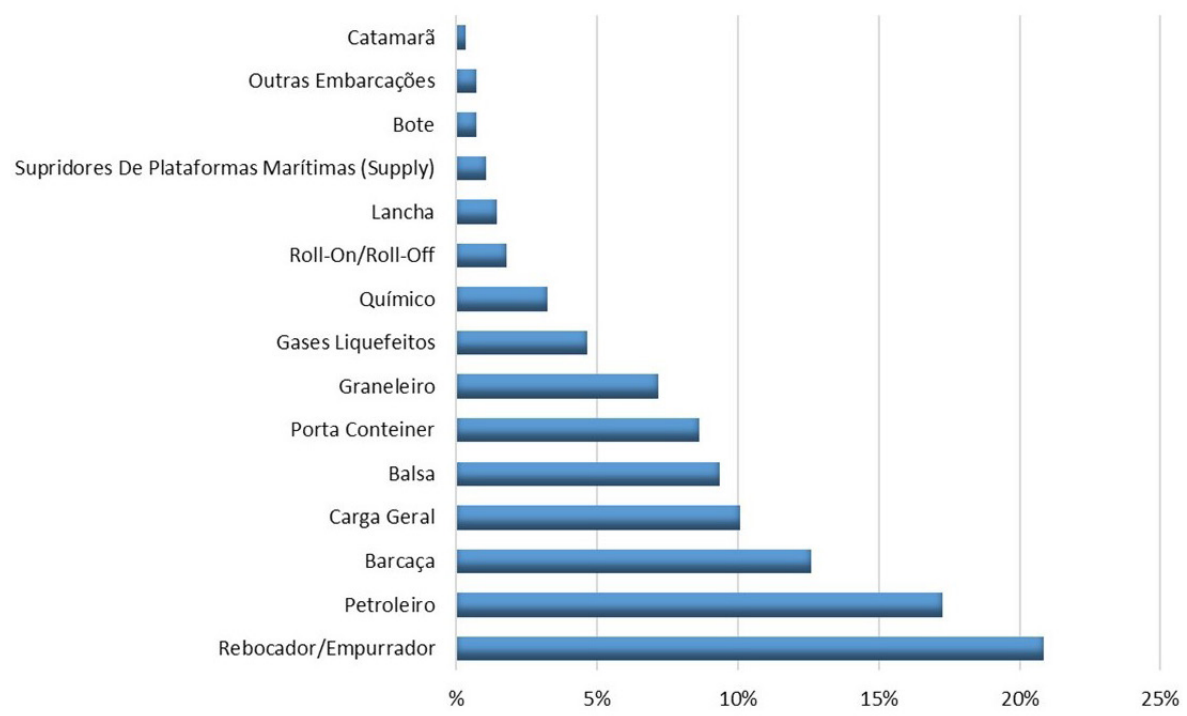

Figura 7. Participação da frota de cabotagem por tipo de embarcação em 2017. Fonte: Adaptação própria com base nos Anuários Estatísticos Portuários da Antaq (Antaq, 2017).

A média de idade geral das embarcações que servem a cabotagem das EBNs ${ }^{11}$ na atualidade é de 13 anos, uma idade média operacional que foi reduzida como parte dos reflexos dos investimentos realizados pelos programas navais inseridos, sobretudo nas duas primeiras fases do PAC (Figura 8). No período de 2010 a 2017 se observou uma queda acentuada da medida de idade, mas uma nova tendência de crescimento a partir de 2016.

11. Segundo Lei Federal, Empresa Brasileira de Navegação é uma pessoa jurídica constituída segundo as leis brasileiras, com sede no País, que tenha por objeto o transporte aquaviário, autorizada a operar pelo órgão competente (Brasil, 1997). 


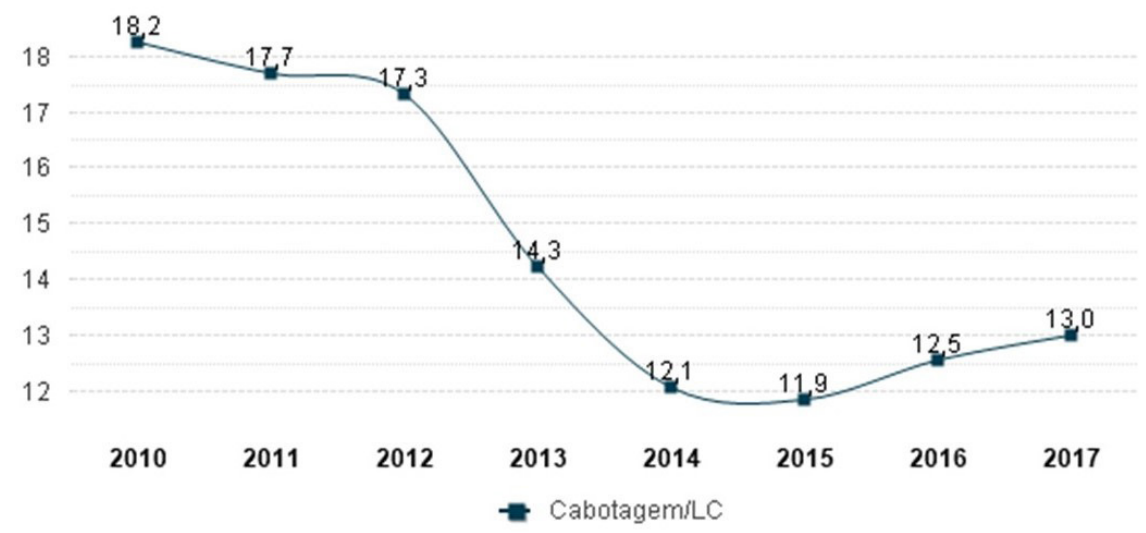

Figura 8. Idade média da frota por outorga para cabotagem da EBN dentre 2010 e 2017. Fonte: Adaptação própria com base nos Anuários Estatísticos Portuários da Antaq (Antaq, 2017).

Em vista disso, o modal aquaviário novamente passa por uma fase importante, pois caso a idade operacional volte a crescer drasticamente e a demanda por novas embarcações não seja atendida, os custos operacionais crescerão e novamente o modal poderá declinar frente a concorrência com as modalidades terrestres, bem como em relação aos outros desafios decorrentes.

Destarte, para além da análise dos sistemas de engenharias de movimento, observa-se que na atualidade a movimentação de carga através da cabotagem no Brasil possui uma tendência de crescimento, em vista disso, é fundamental analisar mais detalhadamente essa circulação material pelo território. ${ }^{12}$

Assim, o Anuário Estatístico da Antaq (2017) nos oferece uma rica base de dados sobre o modal aquaviário brasileiro. Em grande parte, o Sistema de Desempenho Portuário (SDP) é a principal fonte de dados para as estatísticas referentes ao transporte de mercadorias na navegação de cabotagem no Brasil, sendo alimentado com os dados de movimentação de carga que cada autoridade portuária periodicamente envia sobre os portos ou terminais portuários sob sua gestão.

Considerando a tonelagem transportada em 2017, nota-se que há uma concentração operacional nas instalações portuárias privadas que, conjuntamente, representaram aproximadamente $78,5 \%$ do total movimentado, o restante, $21,5 \%$ do total, foi transportado nos portos públicos (Figura 9).

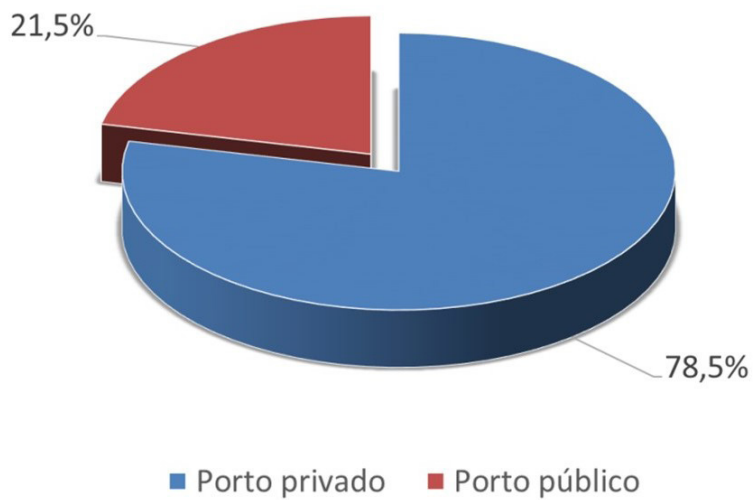

Figura 9. Percentuais e tonelagem da movimentação na cabotagem em 2017. Fonte: Elaboração própria com base no Anuário Estatístico Portuário 2017 (Antaq, 2017).
12. Parte das análises estatísticas relatadas neste artigo foram realizadas por Fonseca (2012), outras são decorrentes de análises atuais. 
Por conseguinte, verifica-se que são nos fixos portuários privados onde se realizam a maior parte das operações da cabotagem brasileira no período, restando um percentual minoritário para os fixos portuários que atuam com o objetivo da prestação de um serviço público.

Além da concentração operacional em portos privados, também há uma tendência histórica recente de concentração operacional relevante em apenas alguns desses portos que se repete nos últimos anos (Fonseca, 2012).

Assim sendo, as análises estatísticas realizadas em Fonseca (2012) revelaram que neste início de século XXI os principais portos públicos (fixos) na dinâmica da navegação de cabotagem brasileira são oito, a saber: Santos/SP, Vila Conde/PA, Suape/PE, Itaqui/ MA, Fortaleza/CE, Paranaguá/PR, Rio Grande/RS, além de Belém/PA, onde apesar da quantidade absoluta movimentada não ser tão expressiva, a cabotagem representa quase metade de suas operações.

Em relação aos portos privados considerando os sete terminais com maior movimentação em tonelagem em 2011 têm-se: Almirante Barroso (São Sebastião/SP), Almirante Maximiliano Fonseca (Angra dos Reis/RJ), Madre de Deus/BA, Trombetas (Oriximiná/ PA), Almirante Tamandaré (Rio de Janeiro/RJ), Alumar (São Luís/MA) e Transpetro-São Francisco do Sul/SC; que conjuntamente movimentaram aproximadamente $60 \%$ da tonelagem da cabotagem brasileira (Fonseca, 2012).

Sendo assim, é marcante o fato de que no Brasil há mais de duas centenas de fixos portuários e uma costa de milhares de quilômetros, no entanto as operações vinculadas à navegação de cabotagem estão concentradas em apenas alguns pontos do território brasileiro. A distribuição territorial desses fixos portuários pode ser visualizada na Figura 10.

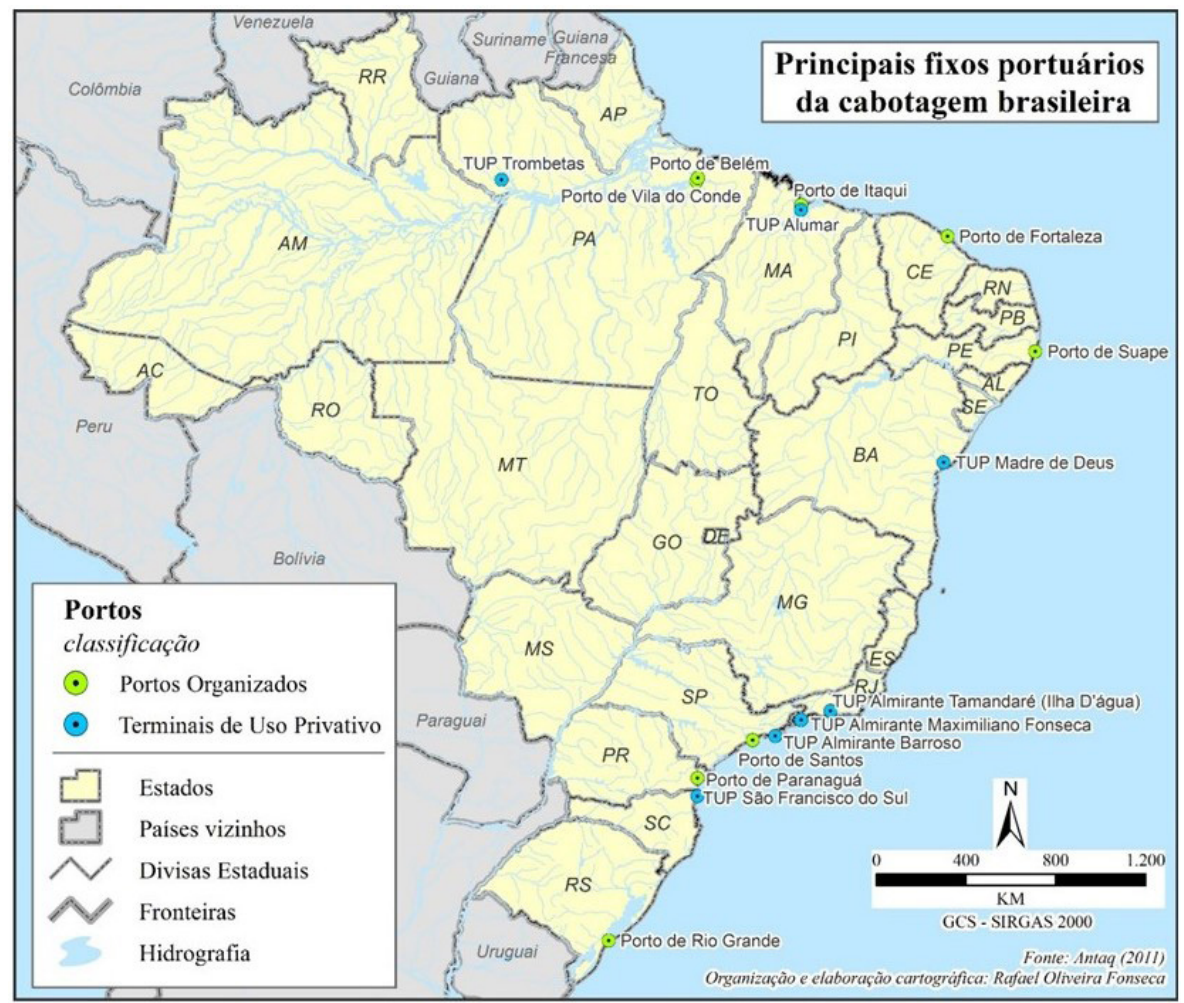

Figura 10. Principais fixos portuários da cabotagem brasileira. Fonte: elaboração própria (ANTAQ 2011). 
Em 2011 foram movimentados nesses fixos portuários 76,8\% de toda cabotagem brasileira (Quadro 3), revelando uma relevante concentração operacional nesses 15 portos. Apenas o TUP Almirante Barroso da Petrobras, localizado em São Sebastião/SP, movimentou sozinho $21 \%$ do total (Fonseca, 2012).

Para avançar na análise dos fluxos para além de uma perspectiva quantitativa e, consequentemente, ampliar-se a compreensão dos motivos dessa concentração operacional em apenas alguns pontos do território nacional, considera-se fundamental esclarecer quais tipos de mercadorias trafegam pelas rotas marítimas da cabotagem brasileira.

Quadro 3. Movimentação de cabotagem nos principais fixos portuários (2011). Fonte: Fonseca (2012).

\begin{tabular}{|c|c|c|c|c|c|}
\hline Tipo & Nome & Município/UF & Responsável & Total (ton) & $\begin{array}{l}(\%) \\
\text { total }\end{array}$ \\
\hline TUP & Almirante Barroso & São Sebastião/SP & Petrobras & 40.550 .810 & $21 \%$ \\
\hline TUP & Almirante Max.Fonseca & Angra dos Reis/RJ & Petrobras & 17.919 .256 & $9,3 \%$ \\
\hline TUP & Madre de Deus - Transpetro & Madre de Deus/BA & Petrobras & 17.491 .000 & $9,0 \%$ \\
\hline TUP & Porto Trombetas & Oriximiná/PA & Mineração rio do Norte S/A & 11.374 .666 & $5,9 \%$ \\
\hline TUP & Almirante Tamandaré & Rio de Janeiro/RJ & Petrobras & 9.943 .592 & $5,1 \%$ \\
\hline$P O$ & Santos & Santos/SP & Cia. Docas do Est. de São Paulo - Codesp & 9.262 .296 & $4,8 \%$ \\
\hline TUP & Alumar & São Luís/MA & Consórcio de Alumínio do Maranhão & 9.121 .602 & $4,7 \%$ \\
\hline$P O$ & Vila do Conde & Barcarena/PA & Cia. Docas do Pará - CDP & 7.593 .876 & $3,9 \%$ \\
\hline TUP & São F. do Sul - Transpetro & São F. do Sul/SC & Petrobras* & 7.385 .783 & $3,8 \%$ \\
\hline$P O$ & Suape & Ipojuca/PE & Suape Complexo Industrial Portuário & 6.059 .242 & $3,1 \%$ \\
\hline$P O$ & Itaquí & São Luís/MA & Emp. Maranhense de Adm. Portuária & 3.234 .409 & $1,7 \%$ \\
\hline$P O$ & Fortaleza & Fortaleza/CE & Companhia Docas do Ceará - CDC & 2.479 .909 & $1,3 \%$ \\
\hline$P O$ & Paranaguá & Paranaguá/PR & Adm. dos Portos de Paranaguá e Antonina & 2.358 .946 & $1,2 \%$ \\
\hline PO & Rio Grande & Rio Grande/RS & Sup. do Porto de Rio Grande - SUPRG & 2.158 .476 & $1,1 \%$ \\
\hline PO & Belém & Belém/PA & Cia. Docas do Pará - CDP & 1.572 .323 & $0,8 \%$ \\
\hline \multicolumn{4}{|c|}{ Subtotal } & 148.506 .186 & $76,8 \%$ \\
\hline TUP & \multicolumn{3}{|c|}{ outros Terminais de Uso Privativo (49 TUP) } & 35.919 .088 & $18,6 \%$ \\
\hline PO & \multicolumn{3}{|c|}{ outros Portos Organizados (18 PO) } & 9.044 .066 & $4,7 \%$ \\
\hline \multicolumn{4}{|c|}{ TOTAL } & 193.469 .340 & $100 \%$ \\
\hline
\end{tabular}

Posto isto, com o objetivo de realizar uma análise mais detalhada de como a cabotagem se insere na divisão territorial do trabalho e nos circuitos espaciais da produção do Brasil, é relevante investigar a movimentação por Grupo de Mercadorias.

Assim, em 2017, uma diversidade de mercadorias foi movimentada através da navegação de cabotagem no Brasil (31 Grupos de Mercadorias). No entanto, verifica-se que apenas três desses Grupos foram responsáveis conjuntamente por 93,2\% do total movimentado pela cabotagem brasileira no período (Figura 11) (Antaq, 2017). 


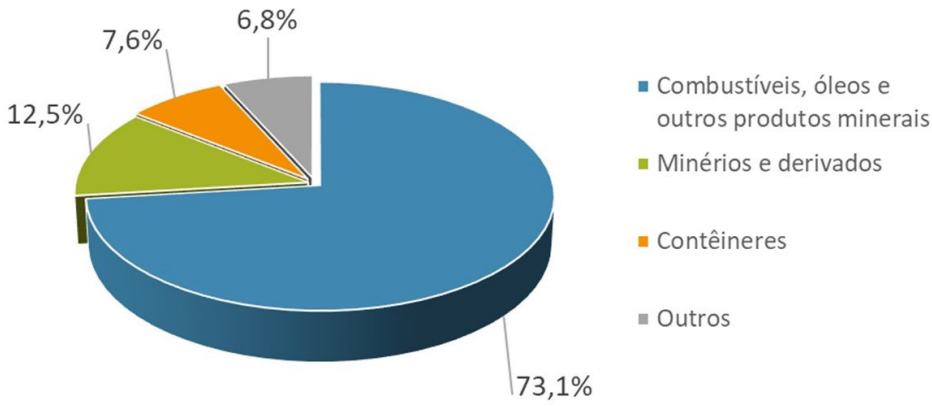

Figura 11. Movimentação de cabotagem nos Fixos Portuários em 2017 por Grupo de Mercadorias. Fonte: Elaboração própria com base em Anuário Estatístico Portuário 2009 (Antaq, 2009).

Nessa perspectiva, nota-se evidentemente que há no Brasil o predomínio do transporte de insumos produtivos (commodities minerais). Destaca-se que a movimentação de contêineres, apesar de estar dentre as três maiores, representa um percentual de apenas 7,6\% do total.

É possível que as razões dessa baixa expressividade possuam relação com as deficiências infraestruturais brasileiras no contexto da intermodalidade, além dos marcantes aspectos culturais nas operações logísticas brasileiras. O país é essencialmente rodoviarista há décadas, apesar de muitos armadores ${ }^{13}$ oferecerem serviços logísticos de linhas regulares na cabotagem, conforme destaca Fonseca (2012).

Isto posto, compreende-se que a análise dos fluxos dessas mercadorias predominantes, nos permitem uma melhor concepção dos fluxos que compõem a dinâmica territorial brasileira, a partir da cabotagem e sua relação marcante com alguns circuitos espaciais da produção.

A análise dos fluxos desses insumos produtivos predominantes (petróleo e bauxita) realizado por Fonseca (2012) nos permite uma mais acurada compreensão das operações que envolvem a navegação de cabotagem, mas também da dinâmica territorial e das interações espaciais decorrentes de tais circuitos produtivos.

Ullman (1972) considera que as interações espaciais contribuem para a compreensão de interdependência entre áreas geográficas distintas, tendo como base três fatores distintos: 1) complementaridade, com a necessidade de ocorrer demanda e oferta entre duas áreas para que a interação ocorra no espaço através da circulação; 2) oportunidade mediadora, ajudando a criar as interações espaciais através de rotas consideradas vantajosas; e a 3) transmissibilidade espacial, trata-se das possibilidades de movimentação dos produtos em condições consideradas economicamente viáveis.

Em 2011, os circuitos produtivos que mais movimentaram mercadorias através da navegação de cabotagem brasileira foram: do petróleo e seus derivados, e do alumínio (bauxita). Juntos atingiram aproximadamente 155 milhões de toneladas (Fonseca, 2012).

No circuito do petróleo, os fluxos estão centralizados próximos a região concentrada do país onde logicamente se localiza os principais centros consumidores dos produtos oriundos desse circuito, além de estarem atrelado às áreas produtoras de petróleo próximas ao litoral brasileiro.

No entanto, cabe destacar que além da cabotagem o circuito produtivo do petróleo e seus derivados também se utiliza largamente de dutovias que interligam os fixos portuários aos locais, por exemplo, de produção de derivados (refinarias), através de uma rede de milhares de quilômetros, estabelecendo assim um circuito assinalado por uma rede técnica que interliga os terminais com a hinterlândia.
13. Pessoa física ou jurídica que explora comercialmente uma embarcação mercante, sendo ou não seu proprietário. 
Sobre o circuito produtivo do alumínio (que tem como matéria primária a bauxita), verifica-se que em 2009 ocorreram alguns fluxos pontuais basicamente no Pará e Maranhão, com embarques no TUP de Trombetas (Oriximiná/PA) e desembarques no Porto Vila do Conde (Barcarena/PA) e no TUP da Alumar (São Luís/MA) (Fonseca, 2012).

Essa análise destacou a ocorrência de uma concentração dos fluxos nesses portos e, além disso, revelou uma distribuição territorial do circuito do alumínio marcada por uma concentração operacional em apenas alguns pontos do Brasil. Os estados do Pará, Maranhão, Minas Gerais e São Paulo, são as bases principais desse circuito, atrelada também ao papel de suas malhas ferroviárias largamente utilizadas no Brasil para a movimentação de recursos minerais sólidos, como é o caso da bauxita. As unidades produtivas desse minério, em geral, localizam-se as margens da malha férrea nacional, sobretudo em Minas Gerais, São Paulo e Rio de Janeiro (Figura 12).

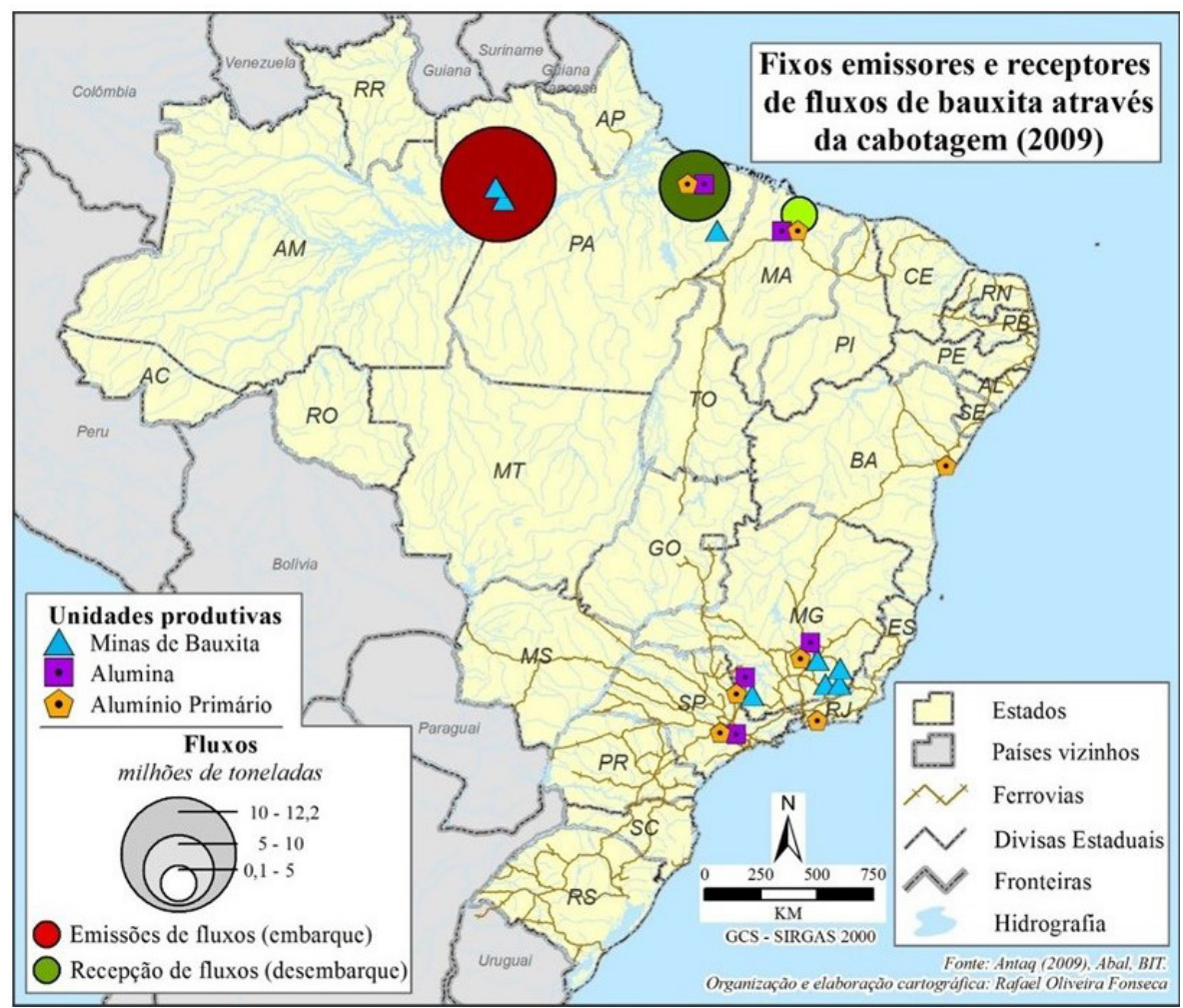

Figura 12. Fixos emissores e receptores de fluxos de bauxita através da cabotagem em 2009. Fonte: elaboração própria (Antaq, 2011).

Em conclusão, destaca-se o fundamental papel da cabotagem como base da circulação do circuito produtivo do alumínio, por meio de uma rede técnica que interliga vários pontos que se espalham pelo território brasileiro. No entanto, o circuito produtivo do petróleo e seus derivados ainda é o principal operador da cabotagem brasileira, por isso, para complementar essa análise faz-se necessário enfatizar o papel e as influências da Petrobras para essa modalidade de transporte aquaviário.

\section{Petrobras: o principal "cabotador" do Brasil}

Criada em 1953, a Petrobras é uma sociedade anônima de capital aberto do qual o acionista majoritário é o Estado brasileiro. A empresa atua largamente nos setores de: exploração e produção, refino, petroquímica, distribuição de derivados, energia elétrica, biocombustíveis, outras fontes renováveis de energia, comercialização, e transporte 
de óleo e gás natural. Se situa dentre as maiores companhias do mundo em valor de mercado e atua em mais de 19 países, sendo reconhecida mundialmente por sua tecnologia de exploração de petróleo em águas ultraprofundas, como, no caso do pré-sal.

A Transpetro S/A, criada em 1988, é uma subsidiária da Petrobras e atende a maior parte de suas demandas em relação às atividades de transporte e armazenamento de petróleo e derivados, etanol, biocombustíveis e gás natural, unindo as áreas de produção, refino e distribuição do sistema Petrobras, inclusive nos processos de importação e exportação.

A subsidiária tem a Petrobras como seu principal cliente, mas também é prestadora de serviços à diversas distribuidoras e indústrias petroquímicas do pais com instalações em 20 estados da federação. A companhia é a maior armadora da América Latina e está dentre as principais empresas de logística e transporte do país.

Isto posto, a Petrobras é o principal agente na dinâmica das circulações que perpassam pela cabotagem brasileira. Além do mais, está diretamente atrelada a quase totalidade das iniciativas públicas e privadas que têm por objetivo realavancar o setor da indústria naval nacional, com a encomenda de centenas de novas embarcações através do Programa de Modernização e Expansão da Frota (Promef) e do Programa de Renovação da Frota de Apoio Marítimo (Prorefam), que integrara o PAC em todas suas fases.

Para promoção da circulação de sua produção, além da maior frota de navios do país, a companhia possui milhares de quilômetros de dutos que perpassam por 48 terminais da Transpetro, sendo 20 terrestres e 29 marítimos que funcionam como entrepostos intermodais, interligando o sistema com a hinterlândia (Fonseca, 2012). A dimensão continental do país obriga a empresa a operar uma grande quantidade de fixos, de navios e uma considerável extensão de dutos que interligam as regiões produtoras, de refino e de distribuição dos produtos do circuito produtivo da companhia.

Do ponto de vista quantitativo, em 2011 a companhia movimentou em seus Terminais de Uso Privativos aproximadamente 108 milhões de toneladas dentre petróleo, combustíveis, óleos minerais, e derivados (Quadro 4). Essa tonelagem é o equivalente a 56\% da movimentação total de carga via cabotagem brasileira no período (Antaq, 2011).

Quadro 4. Movimentação de carga nos Terminais de Uso Privativo da Petrobras em 2011. Fonte: Elaboração própria com base em Anuário Estatístico Aquaviário 2011 (Antaq, 2011)

\begin{tabular}{|l|c|c|c|}
\hline Terminal de Uso Privativo & Município/UF & Tonelagem & (\%) do total \\
\hline Almirante Barroso & São Sebastião/SP & 40.550 .810 & $37,6 \%$ \\
\hline Almirante Maximiliano Fonseca & Angra dos Reis/RJ & 17.919 .256 & $16,6 \%$ \\
\hline Madre de Deus - Transpetro & Madre de Deus/BA & 17.491 .000 & $16,2 \%$ \\
\hline Almirante Tamandaré & Rio de Janeiro/RJ & 9.943 .592 & $9,2 \%$ \\
\hline São F. do Sul - Transpetro & São F. do Sul/SC & 7.385 .783 & $6,8 \%$ \\
\hline Almirante Soares Dutra & Osório/Tramandaí/RS & 4.741 .954 & $4,4 \%$ \\
\hline Carmópolis & Aracaju/SE & 3.207 .015 & $3,0 \%$ \\
\hline Guamaré & Guamaré/RN & 2.838 .762 & $2,6 \%$ \\
\hline Manaus & Manaus/AM & 2.552 .694 & $2,4 \%$ \\
\hline Norte Capixaba & São Mateus/ES & 902.327 & $0,8 \%$ \\
\hline Dunas & Natal/RN & 240.727 & $0,2 \%$ \\
\hline Ilha Redonda - Transpetro & Rio de Janeiro/RJ & 139.161 & $0,1 \%$ \\
\hline Solimões & Coari/AM & 71.083 & $0,1 \%$ \\
\hline T O T A L & & 107.984 .164 & $100 \%$ \\
\hline
\end{tabular}

Dessa forma, parece evidente o papel da companhia na cabotagem brasileira. Apenas a Petrobras movimentou em 2011 mais da metade da tonelagem que perpassou pela navegação de cabotagem do Brasil (Antaq, 2011). 
Por isso, o Terminal Almirante Barroso (Tebar), localizado no litoral do estado de São Paulo no município de São Sebastião, se coloca como principal fixo portuário na navegação de cabotagem brasileira e um dos maiores terminais de óleos e derivados da América Latina. Sua movimentação em 2011 de 40 milhões de toneladas representou 21\% do total da cabotagem do país no período. ${ }^{14}$ Se trata de um percentual extremamente relevante para um só porto de um país continental, considerando que nesse ano, a Antaq contabilizou movimentação de cabotagem em 82 portos e terminais do país (Antaq, 2011).

Em suma, a importância da companhia para a navegação de cabotagem brasileira, bem como para a indústria naval é incontestável, seja pela quantidade de fixos ou pelos imensos fluxos materiais decorrentes de seus circuitos produtivos.

\section{Considerações finais}

Concebemos que a circulação, seja ela material ou imaterial, é um elemento intrínseco aos processos produtivos e se estabelece como uma das premissas do período atual comandado pela racionalidade econômica capitalista mundializada. É axiomático que os circuitos espaciais da produção demandam incessantemente essa racionalidade com base, sobretudo, na fluidez e na porosidade territorial, buscando sempre efetivar a supressão dos obstáculos para a livre circulação das mercadorias, das informações, bem como do dinheiro.

Nesse cenário, apesar de cada vez mais fluído e poroso, o espaço geográfico tende a adensar-se, dispondo de sistemas técnicos e normativos que atendam aos interesses dos agentes hegemônicos corporativos, e consequentemente promovendo: o aumento dos fluxos materiais e imateriais, a expansão da divisão social e territorial do trabalho, aprofundando a especialização produtiva e a hierarquização dos lugares, bem como de outras manifestações peculiares do processo de mundialização do capital.

Em vista disso, neste início de século XXI perfilou-se um novo ciclo governamental no Brasil e uma conjuntura macroeconômica internacional que posicionou o país em um momento diferenciado de sua história ampliando sua importância política e econômica no cenário internacional.

O país perpassou por mais de uma década por algumas transformações internas relevantes, quando várias políticas públicas de desenvolvimento econômico estiveram em pauta atreladas a um processo de investimentos sociais. Foi um processo que manteve ao mesmo tempo continuidade e ruptura, acarretando na manifestação de uma nova conjuntura pelo território de forma profunda, mas que enfrenta grandes dificuldades de consolidação.

No entanto, verificou-se que naquele momento o Estado gradativamente retomou o papel indutor direto da economia, incentivando, mas principalmente alocando relevantes montantes financeiros no setor de transportes por meio de programas públicos conforme abordado por este trabalho. Também é fato que a criação da Antaq, como órgão regulador e fiscalizador foi um importante marco para a navegação de cabotagem apesar das inúmeras críticas as agências reguladoras brasileiras.

As análises das estatísticas atuais revelam que apesar de estarmos em um cenário de crises econômicas "momentâneas", que se tornam cada vez mais permanentes, a cabotagem cresce e possui uma frota que ultrapassa 200 embarcações. No entanto, o recenseamento também revela que há uma concentração marcante em relação aos fixos e aos fluxos que se utilizam dessa modalidade de transporte aquaviário.
14. O Tebar abastece quatro refinarias do estado de São Paulo: Paulínia (Replan), Vale do Paraíba (Revap - São José dos Campos), Capuava (Recap - Santo Andrél Mauá) e Presidente Bernardes (RPBC - Cubatão). O transporte terrestre é realizado por oleodutos. O Tebar possui destaque para a movimentação de derivados de petróleo tanto na escala estadual quanto nacional, ocasionando impactos diretos no espaço urbano de São Sebastião, já que sua infraestrutura se interpõe à estrutura urbana da cidade, ou seja, influência diretamente na dinâmica da hinterlândia local (Reis, 2011). 
Em relação às operações portuárias, observa-se que apenas alguns portos e terminais privados concentram quase que a totalidade das operações da cabotagem no Brasil. Da mesma forma, quando se analisa os fluxos, verifica-se a importância desse modal para a movimentação de insumos produtivos atrelados a apenas alguns circuitos produtivos, basicamente do petróleo e do alumínio.

No circuito do petróleo é interessante destacar que os fluxos se concentram logicamente próximo as áreas produtoras de petróleo e a região concentrada do país onde há maior demanda de seus derivados. No circuito do alumínio (baseado na bauxita) os principais fluxos ocorrem basicamente no Pará e Maranhão, apesar deste circuito também se utilizar em larga escala do modal ferroviário com unidades extratoras de minérios e produtoras de alumínio às margens da rede férrea, sobretudo na Região Sudeste do Brasil.

Ainda em relação aos fixos e fluxos vinculados as operações da cabotagem brasileira é axiomático o papel da Petrobras (e de sua subsidiária Transpetro) como principal "cabotador" do país, seja em relação a tonelagem transportada, a quantidade de terminais portuários ou a sua imensa frota de embarcações.

Suas atividades produtivas direcionam claramente as políticas públicas para a navegação de cabotagem no Brasil, seja nos investimentos em portos ou nos programas direcionados a indústria naval e atrelados a renovação da marinha mercante nacional.

Isso estabelece uma contradição em relação ao discurso e as ações do Estado brasileiro, visto que algumas políticas públicas para o setor dos transportes preveem em suas diretrizes uma tendência de equilíbrio entre os modais da matriz de transporte brasileira no futuro, mas as ações práticas dos últimos anos parecem reforçar o papel do transporte terrestre nesse país de tamanho continental.

Por isso é imprescindível considerar a Petrobrás como o principal agente da cabotagem brasileira na atualidade em uma perspectiva que tende a ser duradoura, visto a dificuldade do país no contexto da intermodalidade dos transportes.

Assim, este trabalhou destacou alguns elementos que envolve a cabotagem no Brasil, no entanto, reforça-se que essa modalidade de transporte poderia ser ampliada de maneira a se favorecer das características físicas do território nacional, sobretudo pelo fato do país possuir uma imensa costa atrelada a uma concentração populacional predominantemente litorânea.

Um maior equilíbrio dentre os modais defendido em algumas diretrizes estatais, se ocorrer, poderá promover uma expansão do uso do modal aquaviário, podendo conferir significativas alterações em circuitos espaciais da produção que praticamente irão descobrir tal modalidade de transporte, o que é imensa contradição no contexto da revolução técnico-científica.

De qualquer maneira, como efeito, uma expansão da intermodalidade acarretaria em uma nova (re)organização do território nacional, provocando efeitos sobre suas interações espaciais, na especialização e hierarquização dos lugares, e consequentemente em alterações na divisão territorial do trabalho, além de um novo impulso à indústria naval realavancando todo um circuito produtivo que por décadas ficou estagnado e somente nos últimos anos foi "reativado", mas ainda navega lentamente enfrentando o atual cenário nebuloso não só da economia mas também da política nacional brasileira.

Por fim, é preciso aguardar a superação do cenário de incertezas a curto prazo para então se retomar uma análise acerca do futuro da cabotagem brasileira. 


\section{Q Bibliografia}

» Arroyo, M. M. (2001). Território brasileiro e mercado externo: uma leitura do Brasil na virada do século XX. 250 p. Tese. (Doutorado em Geografia Humana). Faculdade de Filosofia, Letras e Ciências Humanas da Universidade de São Paulo, Departamento de Geografia. São Paulo/SP.

» Arroyo, M. M. (2006). Dinâmica territorial, circulação e cidades médias. In: Eliseu S. Sposito; Maria E. B. Sposito; Oscar Sobarzo (orgs.). Cidades Médias: Produção do espaço urbano e regional. São Paulo: Expressão Popular, p. 71-85.

» Bichou, K.; Gray, R. (2005). A critical review of conventional terminology for classifying seaports. Transportation Research. Part A: Policy and Practice 39 (1), 75-92.

》 Braudel, F. (1996). Civilização matéria, economia e capitalismo. Século XV-XVIII, vol. 2, Os jogos das trocas. São Paulo: Martins Fontes, 1979, p. 11-93.

"Castillo, R. (2011). Agricultura globalizada e logística nos cerrados brasileiros. In: SILVEIRA, Márcio R. (Org.). Circulação, transportes e logística: Diferentes perspectivas. São Paulo: Outras Expressões, p. 331-354

》 Castillo, R.; Frederico, S. (2010). Espaço geográfico, produção e movimento: uma reflexão sobre o conceito de circuito espacial produtivo. Sociedade \& Natureza, Uberlândia 22 (3), dez. Disponível em: <http://www.sociedadenatureza.ig.ufu.br>

"CNT - CONFEDERAÇÃO NACIONAL DO TRANSPORTE (2014) Pesquisa Rodoviária - Relatório Gerencial. Brasília: Confederação Nacional do Transporte.

»Contel, F. B. (2001). Os sistemas de movimento do território brasileiro. In: SANTOS, Milton; SILVEIRA, Maria Laura. O Brasil: território e sociedade no século XXI. $3^{\mathrm{a}}$ ed. Rio de Janeiro: Record, p. 329-343.

》 Corrêa, R. L. (1997). Interações Espaciais. In: Iná E. Castro; Paulo C. C. Gomes; Roberto L. Corrêa (orgs.). Explorações geográficas: percursos no fim do século. Rio de Janeiro: Bertrand, p. 279-318.

»Cruz, R. (2006a). Geografia da Atividade Portuária Contemporânea. In: Qualidade Ambiental e Atividade Portuária no Brasil/Rio Grande. Material de treinamento: Ministério do Meio Ambiente e TSC Brasil, Rio Grande.

»Cruz, R. (2006b). Geografia do Sistema Portuário Brasileiro. In: Qualidade Ambiental e Atividade Portuária no Brasil/Rio Grande. Material de treinamento: Ministério do Meio Ambiente e TSC Brasil, Rio Grande, 2006b.

»Felipe JR., N. F.; Silveira, M. R. (2009). A Hidrovia Tietê-Paraná e o porto intermodal de Pederneiras-SP. In SILVEIRA, Márcio R.; LAMOSO, Lisandra P.; MOURÃO, Paulo F. C. (Orgs.). Questões nacionais e regionais do território brasileiro. São Paulo: Expressão Popular, p. 219-244.

» Felipe JR., N. F. (2012). O transporte marítimo de cabotagem e longo curso e sua importância para a economia brasileira. 311 p. Tese. (Doutorado em Geografia). Faculdade de Ciência e Tecnologia da Universidade Estadual Paulista - Unesp. Presidente Prudente/SP.

"Fischer, A. (2009). Os portos marítimos: tentativa de classificação. In: SPOSITO, E. (Org.). Indústria, ordenamento do território e transportes. São Paulo: Expressão Popular, 1963, p. 133-155. 
»Fonseca, R. O. (2012). A circulação através da navegação de cabotagem no Brasil: um sistema de fluxos e fixos aquaviários voltados para a fluidez territorial. 188p. Dissertação (Mestrado em Geografia Humana). Faculdade de Filosofia, Letras e Ciências Humanas da Universidade de São Paulo, Departamento de Geografia. São Paulo/SP.

» Harvey, D. (2005). A produção capitalista do espaço. São Paulo; Annablume.

»IBGE - INSTITUTO BRASILEIRO DE GEOGRAFIA E ESTATÍSTICA (2015) Atlas geográfico escolar: ensino fundamental do $6^{\circ}$ ao $9^{\circ}$ Ano. Rio de Janeiro. IBGE.

"Lamoso, L. P. (2009). A infraestrutura como elemento organizador do território. In: SILVEIRA, Márcio R; LAMOSO, Lisandra Pereira; MOURÃO, Paulo F. C. (Orgs.). Questões nacionais e regionais do território brasileiro. São Paulo. Expressão Popular, p. 43-62.

» Medina, A. C. et al. (2010). Análise da competitividade da indústria marítima brasileira e um panorama do setor de cabotagem no Brasil e no exterior: uma visão da indústria da construção naval brasileira e seus principais atores. São Paulo: Iglu.

» Moraes, A. C. R. (2000). Bases da Formação Territorial do Brasil. São Paulo: Hucitec.

» Moraes, A. C. R. (2007). Contribuições para a gestão da zona costeira do Brasil: elementos para uma Geografia do Litoral Brasileiro. Annablume, São Paulo.

» Neto, R. F. (2010). Análise do Transporte de Carga Marítimo Brasileiro de Longo Curso com Relação a Participação e a Perda de Espaço no Cenário. 106p. Dissertação (Mestrado em Engenharia de Transportes). Instituto Alberto Coimbra de Pós-Graduação e Pesquisa em Engenharia (COPPE) da UFRJ. Rio de Janeiro.

» Prado JR., C. (1977 [1942]). Formação do Brasil Contemporâneo: Colônia. 15 ed. São Paulo: Brasiliense.

» Raffestin, C. (1993). Por uma geografia do poder. São Paulo: Ática, 1980.

»Raspanti, M. (2012). Indústria naval em ritmo mais acelerado. Revista Transporte Moderno. OTM Editora, São Paulo, 454, 58-60.

» Reis, H. S. (2011). O espaço portuário de São Sebastião no contexto da Geografia Portuária Brasileira. 221p. Dissertação (Mestrado em Geografia). Faculdade de Filosofia, Letras e Ciências Humanas da Universidade de São Paulo. São Paulo.

» Rodrigue, J. P.; Comtois, C.; Slack, B. (2009). The Geography of Transport Systems. New York: Routledge, 2009.

»Santos, M. (1994). Técnica, Espaço, Tempo: Globalização e Meio Técnico-Científico Informacional. São Paulo, Hucitec.

"Santos, M. (1996). A Natureza do Espaço. São Paulo, Hucitec.

» Santos, M. (1997 [1988]). Metamorfose do Espaço Habitado. 5. ed. São Paulo, Hucitec.

"Santos, M. (2003). Economia Espacial: Críticas e Alternativas. 2. ed. São Paulo: Edusp, 1979.

"Santos, M. (2008 [1981]). Manual de geografia urbana. 3. ed. São Paulo: Edusp.

»Santos, M.; Silveira, M. L. (2001) O Brasil: território e sociedade no século XXI. $3^{\mathrm{a}}$ ed. Rio de Janeiro: Record. 
» Silva, M. (1941). Geografia dos Transportes no Brasil: IX-Circulação Periférica. Revista Brasileira de Geografia. IBGE, III (2), 374-400.

»Silveira, M. (2009). As cinco revoluções e evoluções logísticas e seus impactos sobre o território brasileiro. In: SILVEIRA, Márcio R; LAMOSO, Lisandra P.; MOURÃO, Paulo F. C. (orgs.). Questões nacionais e regionais do território brasileiro. São Paulo. Expressão Popular, p. 13-42.

"Sposito, E. (1999). Território, logística e mundialização do capital. In: SPOSITO, E. (Org.). Dinâmica econômica, poder e novas territorialidades. Presidente Prudente. GAsPERR/UNESP, p. 99-113.

"Trevisan, L. (2007). Os operadores logísticos e o uso do território brasileiro: racionalidade e fluidez aos circuitos espaciais de produção. 134p. Dissertação (Mestrado em Geografia). Instituto de Geociências da Universidade de Campinas. Campinas/SP.

»Ullman, E. (1972). Geography as spatial interaction. In: HURST, Michael Eliot (org.). Transportation Geography. London: Macgraw Hill, p. 29-39.

»Vallaux, C. (1914). El Suelo y El Estado. Madrid: Daniel Jorro Editor, p. 265-334.

\section{Legislação e documentos oficiais}

» ANTAQ - AGÊNCIA NACIONAL DE TRANSPORTES AQUAVIÁRIOS. (2009). Anuário Estatístico Portuário 2009. Disponível em: <http://www.antaq.gov.br>.

»ANTAQ - AGÊNCIA NACIONAL DE TRANSPORTES AQUAVIÁRIOS. (2010). Anuário Estatístico Aquaviário 2010. Disponível em: <http://www.antaq.gov.br>.

» ANTAQ - AGÊNCIA NACIONAL DE TRANSPORTES AQUAVIÁRIOS. (2011). Anuário Estatístico Aquaviário 2011. Disponível em: <http://www.antaq.gov.br>.

» ANTAQ - AGÊNCIA NACIONAL DE TRANSPORTES AQUAVIÁRIOS. (2012). Anuário Estatístico Aquaviário 2012. Disponível em: <http://www.antaq.gov.br>.

» ANTAQ - AGÊNCIA NACIONAL DE TRANSPORTES AQUAVIÁRIOS. (2013). Anuário Estatístico Aquaviário 2013. Disponível em: <http://www.antaq.gov.br>.

» ANTAQ - AGÊNCIA NACIONAL DE TRANSPORTES AQUAVIÁRIOS. (2014). Anuário Estatístico Aquaviário 2014. Disponível em: <http://www.antaq.gov.br>.

» ANTAQ - AGÊNCIA NACIONAL DE TRANSPORTES AQUAVIÁRIOS. (2015). Anuário Estatístico Aquaviário 2015. Disponível em: <http://www.antaq.gov.br>.

» ANTAQ - AGÊNCIA NACIONAL DE TRANSPORTES AQUAVIÁRIOS. (2016). Anuário Estatístico Aquaviário 2016. Disponível em: <http://www.antaq.gov.br>.

» ANTAQ - AGÊNCIA NACIONAL DE TRANSPORTES AQUAVIÁRIOS. (2017). Anuário Estatístico Aquaviário 2017. Disponível em: <http://www.antaq.gov.br>.

" BRASIL (1997). Lei Federal no 9.432, de 8 de janeiro de 1997. Dispõe sobre a ordenação do transporte aquaviário e dá outras providências. Brasília.

" BRASIL (1998). Ministério dos Transportes. Programa de Desestatização dos Portos: realizações e perspectivas (relatório no 2). Brasília, Fevereiro.

» BRASIL (2001). Lei Federal no 10.233, de 5 de junho de 2001. Dispõe sobre a reestruturação dos transportes aquaviário e terrestre, cria o Conselho Nacional de Integração de Políticas de Transporte, a Agência Nacional de Transportes Terrestres, a Agência Nacional de Transportes Aquaviários e o Departamento 
Nacional de Infraestrutura de Transportes, e dá outras providências. Brasília.

» BRASIL (2004). Lei Federal no 10.893, de 13 de julho de 2004. Dispõe sobre o Adicional ao Frete para a Renovação da Marinha Mercante - AFRMM e o Fundo da Marinha Mercante - FMM, e dá outras providências. Brasília.

» BRASIL (2007). Ministério dos Transportes. Plano Nacional de Logística e Transportes. Brasília.

» BRASIL (2009). Ministério dos Transportes. Relatório Executivo PNLT 2009: Plano Nacional de Logística e Transportes. Brasília.

"BRASIL (2010). Balanço 4 anos (2007-2010) do Programa de Aceleração do Crescimento. $11^{\circ}$ balanço completo. Brasília.

" BRASIL (2012). PAC2 - Programa de Aceleração do Crescimento 2. Relatório de Lançamento. Brasília.

" BRASIL (2013). Lei Federal no 12.815, de 5 de junho de 2013. Dispõe sobre a exploração direta e indireta pela União de portos e instalações portuárias e sobre as atividades desempenhadas pelos operadores portuários; altera as Leis nos 5.025, de 10 de junho de 1966, 10.233, de 5 de junho de 2001, 10.683, de 28 de maio de $2003,9.719$, de 27 de novembro de 1998, e 8.213, de 24 de julho de 1991; revoga as Leis nos 8.630, de 25 de fevereiro de 1993, e 11.610, de 12 de dezembro de 2007, e dispositivos das Leis nos 11.314, de 3 de julho de 2006, e 11.518, de 5 de setembro de 2007; e dá outras providências. Brasília.

» BRASIL (2014). CÔMITE GESTOR DO PAC. PAC2: Balanço 4 anos Final - $11^{\circ}$ Balanço 2011 a 2014. Brasília: Comitê gestor do PAC2.

» BRASIL (2018). CÔMITE GESTOR DO PAC. 6 Balanço do PAC 2015: 2015 - 2018. Brasília: Comitê gestor do PAC.

\section{Rafael Oliveira Fonseca / rafaelfonseca@uems.br - rafa.ofonseca@gmail.com}

Doutor, Mestre, Bacharel e Licenciado em Geografia pela Universidade de São Paulo Brasil (PPGH/DG/FFLCH/USP). Docente na Universidade Estadual de Mato Grosso do Sul (UEMS), nos cursos de Licenciatura e Bacharela em Geografia, na Unidade Universitária de campo Grande. Docente permanente do Programa de Pós-graduação em Estudos Fronteiriços do Câmpus do Pantanal da UFMS (PPGEF/CPAN/UFMS). Membro do grupo de pesquisa GPLAN - Planejamento e Gestão Ambiental (CNPq). 